University of Rhode Island

DigitalCommons@URI

Open Access Master's Theses

1972

\title{
Formation Flight in the Canada Goose (Branta. C. canadensis)
}

Lisa Lofland Gould

University of Rhode Island

Follow this and additional works at: https://digitalcommons.uri.edu/theses

\section{Recommended Citation}

Lofland Gould, Lisa, "Formation Flight in the Canada Goose (Branta. C. canadensis)" (1972). Open Access Master's Theses. Paper 739.

https://digitalcommons.uri.edu/theses/739

This Thesis is brought to you for free and open access by DigitalCommons@URI. It has been accepted for inclusion in Open Access Master's Theses by an authorized administrator of DigitalCommons@URI. For more information, please contact digitalcommons-group@uri.edu. 


\section{FORMATION FLIGHT}

IN THE

CANADA GOOSE

(Branta co canadensis)

BY

LISA LOFLAND GOULD

A THESIS SUBMITTED IN PARTIAL FULFILLMENT OF THE REQUIREMENTS FOR THE DEGREE OF

MASTER OF SCIENCE

IN

ZOOLOGY

UNIVERSITY OF RHODE ISLAND

1972 
MASTER OF SCIENCE THESIS

OF

LISA LOFLAND GOULD

Approved:

The is Committee:

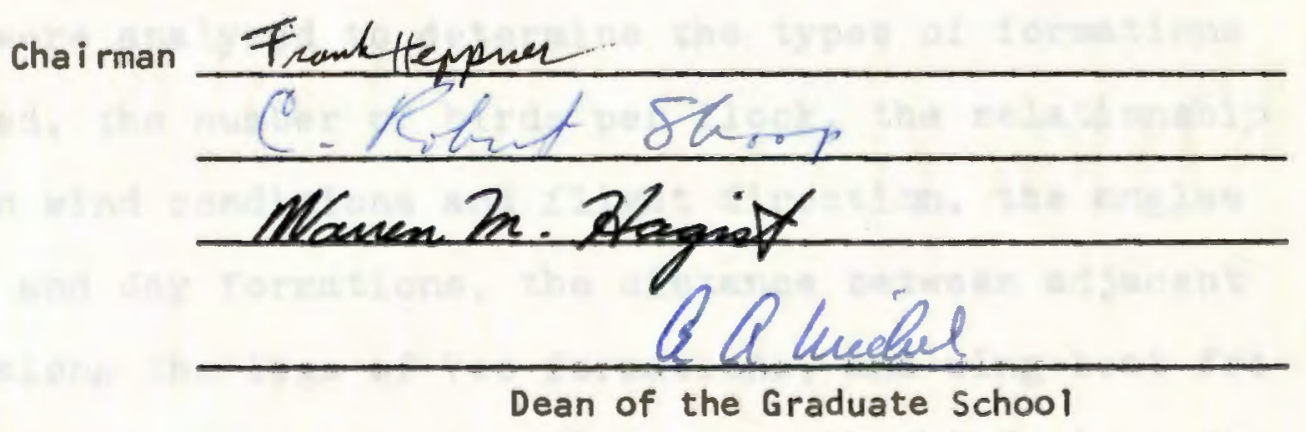

UNIVERSITY OF RHODE ISLAND

1972 


\section{ABSTRACT}

The function of formation flight in Canada Geese and other large waterfowl is unknown, although two hypotheses have been proposed. One hypothesis suggests that formation types are a function of visual and spatial needs; the other suggests that these birds are able to reduce induced drag by formation flight. Published data propose that if formation flight can reduce drag, energy could be saved on long migrations.

In this study, autumnal migrating flocks of Canada Geese (Branta c. canadensis) were filmed at a refuge in upstate New York during early October, 1971. The Super-8mm films were analyzed to determine the types of formations utilized, the number of birds per flock, the relationship between wind conditions and flight direction, the angles of Vee and Jay formations, the distance between adjacent birds along the legs of Vee formations, and wing-beat frequencies and phase relationships among the birds in a formation. This study describes a technique to measure the angles of Vee formations, by the use of three-dimensional descriptive geometry, and is the first study in which formation angles have been measured empirically. The results show formation angles much more acute than previously hypothesized, similar wing-beat frequencies among all birds, 
variable spacing between adjacent birds, and an apparent preference of the majority of the flocks for flight with crosswinds, and at low wind speeds. Due to the variable, and generally large, spacing between adjacent birds along the legs of the formations analyzed, it seems doubtful that these formations could be using the Vee for an aerodynamic advantage. Although the flocks filmed in this study may be more representative of daily movements than of migratory flights, it is possible that the primary function of formation flight may be to maintain flock unity, thus aiding in navigation. Further work is proposed which might resolve the question of a possible aerodynamic advantage to formation flight. 


\section{TABLE OF CONTENTS}

List of Figures $\ldots \ldots \ldots \ldots \ldots \ldots \ldots \ldots \ldots \ldots \ldots \ldots \ldots \ldots \ldots \ldots \ldots \ldots$

List of Tables $\ldots \ldots \ldots \ldots \ldots \ldots \ldots \ldots \ldots \ldots \ldots \ldots \ldots \ldots \ldots \ldots$ vi

Introduction $\ldots \ldots \ldots \ldots \ldots \ldots \ldots \ldots \ldots \ldots \ldots \ldots \ldots \ldots \ldots \ldots \ldots \ldots \ldots \ldots \ldots \ldots \ldots \ldots$

Literature Review ................................ 4

Materials and Methods

1. Data Acquisition ....................... 18

2. Data Analysis .......................... 22

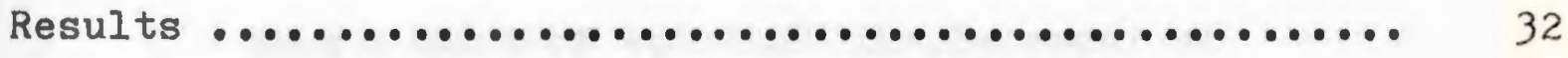

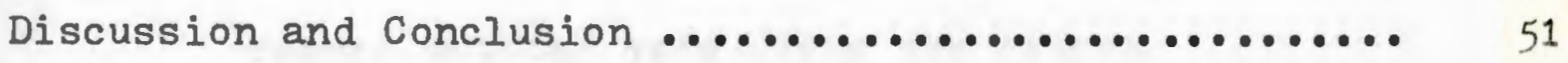

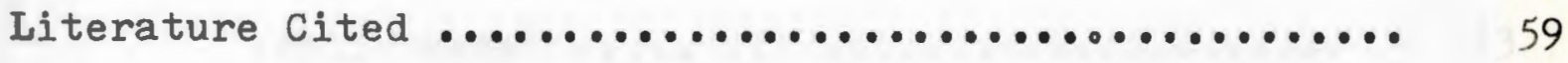




\section{LIST OF FIGURES}

Fig. 1 Hypothetical Vee formation, demonstrating possible distance measurements between two adjacent birds ...................

Fig. 2 Change in apparent angle of a formation, in relation to the angle of the optical

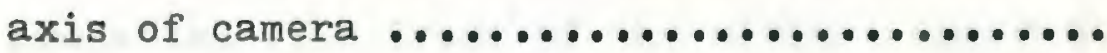

Fig. 3 Change in apparent angle of a formation with change in position of formation, and measurement of vertical displacement of camera optical axis using the tripod inclinometer

Fig. 4 Technique for converting minimal apparent angle of a Vee formation to the true angle ...........................

Fig. 5 Measurement of distance between adjacent birds along the legs of a Vee formation, at the minimal apparent angle .......... 34

Fig. 6 Use of projective geometry to determine true distance between adjacent birds along the legs of a Vee formation

Fig. 7 A Jay formation of 14 birds, traced from the projected film frame of the minimal apparent angle, and showing the calculated regression lines 
Fig. 8 A Vee formation of 12 birds, traced from the projected film frame of the minimal apparent angle, and showing the calculated regression

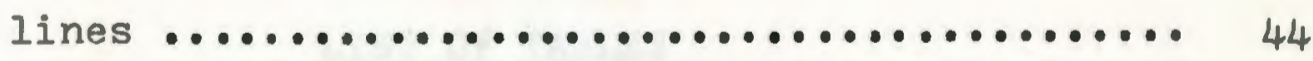

Fig. 9 A vee formation of 9 birds, traced from the projected film frame of the minimal apparent angle, and showing the calculated regression lines

Fig. 10 A Vee formation of 15 birds, traced from the projected film frame of the minimal apparent angle, and showing the calculated regression lines 46

Fig. 11 A Jay formation of 39 birds, traced from the projected film frame of the minimal apparent angle, and showing the calculated regression Iines 


\section{LIST OF TABLES}

Table 1. Types of formation and numbers of birds in each formation type $\ldots \ldots \ldots \ldots \ldots \ldots . . . \ldots 38$

Table 2. Relationship of time of day and observed flocks, and relationship of wind conditions and numbers of flocks .................. 39

Table 3. Distance between adjacent birds along the legs of a formation ................. 48

Table 4. Wing-beat frequencies ................. 49 


\section{ACKNOWLEDGMENTS}

Many have been of assistance and given helpful advice for this thesis. I thank the staff of the Montezuma National Wildlife Refuge for their advice on filming location, and Ms. Louise Stevenson, of the University of North Carolina at Greensboro, for her expert field assistance. Messrs. Jack Favor and Harold Pomeroy, of the Zoology Department, the University of Rhode Island, helped with statistics, and Dr. Alfred Bachelder, of the Engineering Instrument Shop at the University of Rhode Island advised on projective geometry. Mr. Harold Day suggested the original approach to geometry. I am also grateful to Drs. Robert Shoop, of the Zoology Department, and Warren Hagist, Department of Mechanical Engineering, the University of Rhode Island, for the reading of this manuscript.

Dr. Frank Heppner, Department of Zoology, University of Rhode Island, deserves the greatest thanks, for having served as major professor, committee chairman, and friend.

Finally I would like to thank my parents and husband Mark, and the Atlantic Canada Goose, without whom this thesis would not exist. 
"The moment he had left the earth, the wind had vanished. Its restlessness and brutality had dropped away as if cut off by a knife. He was in it, and at peace. "The eight geese spread out in line astern, evenly spaced...They made for the east, where the poor lights had been, and now, before them, the bold sun began to rise. A crack of orange-vermillion broke the black cloudbank far beyond the land. The glory spread, the salt marsh growing visible below.

"The dawn, the sea-dawn and the mastery of ordered flight, were of such intense beauty that the boy was moved to sing. He wanted to cry a chorus to life, and, since a thousand geese were on the wings about him, he had not long to wait. The lines of these creatures, wavering like smoke upon the sky as they breasted the sunrise, were all at once in music and in laughter. Each squadron of them was in different voice, some larking, some triumphant, some in sentiment and glee. The vault of daybreak filled itself with heralds..."

T.H. White The Once and Future King 


\section{INTRODUCTION}

Formation flight in flocks of waterfowl has long been a source of curiosity to observers. Although the Canada Goose (Branta canadensis) is characteristically pictured in the stereotyped Vee formation, this species uses at least eight types of flight formations, and to date no one has been able to determine empirically the function of particular formations. Speculation concerning the significance of the Vee (or similar angular formations, such as the Jay, Compound Vee. Inverted Jay, etc., which are all various types of linear formations; for a complete classification see Heppner, MS.) is present in ornithological literature and hunting lore.

There are two major hypotheses concerning Vee formation functions. One hypothesis suggests that waterfowl, flamingos, pelicans, and other birds fly in linear formation so that each bird, excluding the lead bird, can see ahead and maintain a clear field of vision to the front (Forbush, 1912; Bent, 1925). Geese are gregarious birds, their flocks usually composed of family groups (Collias, 1952): such a behavioral mechanism would permit the members of a family to stay together during flight. A concurrent suggestion is that the spacing observed between birds is a function of the amount of room each bird needs to fly 
without impediment, and the point at which the eyes of a particular bird are best focused on the bird ahead (Poncy, 1941: Van Wormer, 1968: Heppner, MS.).

The second hypothesis considers the aerodynamics of flight, and a possible mechanism flocking birds could use to conserve energy. When a bird (or airplane) flies through the air, there is a force acting against its movement; this force, or backward pressure, is called drag. Part of the total drag is termed "induced drag" and is caused by the rearward inclination of the airflows over and under the wing. At the wing-tips these airflows meet and form a vortex; this wing-tip vortex is the major component of induced drag (Parkinson, 1944; Dwinnell, 1949). Many writers have suggested that birds flying in formations make use of the currents produced by the wing-tip vortices of the birds on either side of them, and are thus able to conserve energy (Munk, 1933; Storer, 1948). Lissaman and Shollenberger (1970) have developed a computer model to calculate the energy savings of birds flying in a Vee formation, and furthermore have suggested that drag can be evenly distributed among the birds in a linear formation, including the lead bird. They proposed that the angle of a formation will depend on the spacing between the birds, and that uniform drag distribution is possible even with uneven spacing.

The theoretical model of Lissaman and Shollenberger has not been confirmed through actual data obtained from 
linear formations of bird flocks. This study presents data on the types of formations used by the Canada Goose (Branta canadensis), the angles of Vee formations, the number of birds in the flocks, the spacing between adjacent birds in a formation, wing-beat frequencies and phase relationships, and relevant meteorological data such as wind speed and directions, and correlates these data with the above hypotheses. 


\section{LITERATURE REVIEW}

The Canada Goose is a social bird, with a close family life. These geese appear to mate for life, and to maintain the family group of one breeding season until the beginning of the following breeding season (Delacour and Mayr, 1945; Elder and Elder, 1949; Beer, 1958). A family may be from 5 to 9 birds (Phillips, 1910: Hanson and Smith, 1950), and migrates as a unit. It has long been believed that large flocks of geese consist of many families (Phillips, 1910; Beer, 1958): Elder and Elder (1949) pointed out that although this is probable, it has not been proved.

The survival value of flocking for long-distance flights has not been determined. Darling (1952) suggested that such social behavior must have some value for the individual bird and the species, but that further analysis was needed. Darling (1938) observed flights previous to migration, in which ever-growing flocks seemed to "practice" flying together; he suggested that these flights were to synchronize mood and flight. Werth (1958) stated that flocking is an innate characteristic, and Lorenz (1937) proposed an automatic releaser--the $V$-shaped stripe of white on the rump of the goose--which could release this behavior. However, geese do not flock throughout the year, so this "releasing" mechanism might not function 
during certain seasons, i.e. the breeding season. Emlen (1952) suggested that among birds there are positive forces which cause mutual attraction, and negative forces of mutual repulsion; these have their bases in innate neural patterns, and are influencec by hormones. Collias (1952) supported this idea by statiing that the decline in gonadal activity after the breeding season reduces territorial behavior, and allows toleramce to flocking.

Once a flock is formed there remains the question of leadership in the formatilon. Leadership can be expressed two ways: flight att the head of a formation, and initiation of behavior for flock. Hanson (1965) stated that the oldest male assumess leadership in situations of danger, but other birds often fly at the head of the flock. Numerous observations have coonfirmed that an old gander does not always lead the formation, and that occupancy of this position frequently changes. This position shift within a formation has been attributed to two possible causes. One is that the leald bird must work harder than the other birds, because it must "break the air" for the other birds (Forbush, 1912: Bent, 1925; Van Wormer, 1968). Heppner (MS.) suggests that remaining in one position causes stimulus fatigue, not only for the lead bird, which must constantly be looking brack to see if the formation is still present, but also $f^{\circ}$ or the other birds who have an unvarying view of the bir ahead. Changing positions might keep the birds more alert and enable them to fly 
further.

Canada Geese are very strong and rapid flyers, and have been recorded at flight speeds up to $106 \mathrm{kph}$ ( $60 \mathrm{mph}$ ) (Van Wormer, 1968). During long-distance flights their speed varies from approximately $70 \mathrm{kph}$ to $106 \mathrm{kph}$ (Queeny, 1947; Van Wormer, 1968); easy cruising flight is approximately 35 to $53 \mathrm{kph}$ (Preston, 1892; Cottam et al, 1942; Tucker and Schmidt-Koenig, 1971). How long these birds can maintain rapid, non-stop flight on their migrations is not known. An average flight period is probably approximately twelve hours; this figure is from personal observations of migrating flocks of geese, which are observed most frequently landing and taking off at sunrise and sunset. Flocks seen at midday are almost always in flight at high altitudes. It would be of interest to follow a flock of geese by air, and determine how long they normally fly non-stop (Pennycuick, 1969).

Flight requires large energy expenditures, perhaps up to 12 times the energy necessary to maintain basal metabolism, or 8 times the resting metabolism (basal metabolism + specific dynamic action) of a bird (Raveling and LeFebvre, 1967). Migration involves protracted flight, and any bird which attempts to migrate successfully must have methods to obtain and conserve the needed energy. One method is to engage in premigratory hyperphagia, and use stored fat to provide energy for migration. Many of the passerines, particularly those which make long over-water migrations, 
utilize this technique (Nisbet, 1963, King and Farner, 1965; George and Berger, 1966). Flight becomes easier as the load lessens, but there is always the danger that the bird will exhaust its energy stores before the trip is over. George and Berger (1966) suggested that there is a fairly wide safety margin in these reserves, but more recent studies by Tucker (1971) suggested that such birds have small safety margins in these long, over-water flights, unless they use additional means to obtain and conserve energy •

The fat stores of heavy birds, such as ducks, geese, and swans, have not been studied. Pennycuick (1969) and Nisbet (1967) suggested that large birds may require more energy per unit weight than do small ones, and are unable to carry as heavy fat loads. Greenewalt (1962) has suggested that the major flight muscles of any bird constitute approximately 17\% of the body weight. As geese and swans have very high wing loadings, in comparison to some of the smaller birds, how are they able to power their flights for long distances, with the same relative amount of muscle but more weight per unit area? Nisbet (1963) concurred with the idea that energy consumed in flight is proportional to body weight, but he also reported a discrepancy in the literature although this theory seems to agree for small birds, the data on large birds are not consistent. Schaefer (1968) offered a possible explanation for this discrepancy, from his studies of the aerodynamics 
of flapping birds. He suggested that the energy needed to fly a certain distance is inversely proportional to the speed of flight. If this is the case, then birds such as ducks and geese (fast flyers) would not require so great a fat load to fly the same distance as would a passerine. In addition, most migrations of the large waterfowl do not involve long over-water flights; probably they are able to obtain much of their energy from frequent feedings (Cone, 1968).

Frequent feeding may not provide all the energy necessary for rapid protracted flight; methods to conserve stored energy may still be needed to insure successful migration. Many birds, instead of constantly utilizing flapping flight, alternate with soaring flight requiring very little energy. Hawks and vultures may soar for hours with only an occasional flap, making use of vertical air currents and favorable winds (Parrott, 1970; Davis, 1896; Raspet, 1950). Other birds, such as cormorants (Phalacrocorax spp.) may conserve energy by alternating a series of flaps with short periods of soaring (Austin, 1961). Geese appear to use constant flapping with no soaring. Pennycuick (1969) has hypothesized that as a secondary soaring technique, these birds might use lee wave systems on their migrations, by flying parallel to and downwind of hills, and flying with a crosswind; this proposal has yet to be demonstrated.

Another way to improve flight efficiency is to reduce 
the amount of drag produced. Drag is the backward pressure exerted on a body moving in a fluid, and it increases as the lift of a body increases. By raising the angle of attack of the wing, lift and drag are increased (drag more rapidly than lift); for any kind of wing there is a certain angle of attack at which the ratio of lift to drag is maximal. When this point is reached, the wing is working at maximum efficiency (Marshall, 1960). The two major components of drag are parasite drag and induced drag. Parasite drag is caused by the surface roughness of the moving body, and by the disturbance of the fluid. It is a direct result of the compressibility and viscosity of the fluid in which the body is moving (Dwinnell, 1949) and of the non-lift-producing portions of the body (Pennycuick, 1969). The importance of the parasite drag increases as the speed of the moving body increases, induced drag decreases in significance as speed increases (Dwinnell, 1949, Lissaman and Shollenberger, 1970). Induced drag is primarily a function of the shape of the wing and the aspect ratio (the ratio of length to mean chord of the wing). If operating at high speeds a low aspect-ratio wing helps reduce parasite drag; at low speeds, a high aspect-ratio will decrease induced drag (Dwinnell, 1949). The most efficient flight speed will be the speed at which induced and parasite drags are equal; the lower these drags, the greater will be the energy saving and possible range increases of the bird. Parasite drag can be reduced by increasing the stream- 
lining of a body, or by changing the fluid in which the body moves (Dwinnell, 1949). Birds have no control over the viscosity of the air, but most flying birds possess very streamlined bodies; Pennycuick (1969) suggested that geese and swans "look" even better streamlined than most birds. Raspet $(1950,1960)$ studied parasite drag of the Black Vulture (Coragyps atratus), and calculated that this bird has very low values for parasite drag. He suggested that streamlining is increased by a boundary layer controlled by the feathers, and that the feathers are "selectively porous", allowing up to ten times more air to pass through the feathers in the downward direction, than in the upward direction. If true, the bird would be aided by increasing the power of the downstroke, and the rapidity of the upstroke, or "recovery stroke" (Cone, 1968). Wind-tunnel studies of live birds, performed by Tucker and Parrott (1970) demonstrated more conventional values for parasite drag, and led Tucker and Parrott to suggest that Raspet's values were due to technical error. The question of feather porosity, particularly in relation to reduction of parasite drag, remains an unsolved and interesting problem.

Reduction of induced drag may be accomplished by several means. Static soaring birds, operating at low speeds and with a fairly low aspect-ratio wing, would appear to have a high induced drag. The presence of "slots" between the primary feathers, however, raises the effective aspect 
ratio; each feather acts as a separate high aspect-ratio wing, the result being that lift is greatly increased and induced drag decreased (Raspet, 1950; Savile, 1957).

The above discussion has dealt with the reduction of drag in fixed-wing aircraft (soaring birds, or man-made airplanes). Before continuing a discussion of drag reduction, it is necessary to study how flapping-wing flight (such as goose flight) differs from fixed-wing flight. A flapping-wing bird is a non-rigid (elastic) flight system, the center of gravity constantly changing with the change in the distribution of mass (Cone, 1968). The shape and position of a flapping wing also is constantly changing, the outer section of the wing propelling the bird, and the inner wing providing lift. In steady flight, the flapping has a regular periodicity. Greenewalt (1960) has suggested that bird wings act as mechanical oscillators, which could be energy-conserving devices (Tucker, 1966). With the constant changes in a flapping wing, the forces acting on each part of the wing also are changing. Thus, calculation of the total lift or drag on such a wing, without knowing every force on every section of the wing, at all times, is extremely difficult (Cone, 1968). Such a calculation has never been made for a flapping wing. Brown (1953) suggested that "a flexible structure such as a bird's wing can have no fixed aerodynamic properties, for these clearly change as the forces on the wing change." For flapping birds, Cone (1968) suggested that the 
induced drag is the largest drag source. Induced drag is caused by the rearward flow of air from above and below the wing; this airflow forms a wake (the vortex wake), strongest at the wing-tips. For fixed-wing aircraft, induced drag can be reduced by changing the effective aspect ratio, or by increasing speed (Dwinnell, 1949). For a flapping wing, this vortex wake becomes very complicated. Cone suggested that the vortex wake and its associated induced drag are the most complicated features of the aerodynamics of the flapping wing, and will be very difficult to compute.

Both Cone (1968) and Raspet (1950) hypothesized that flapping-wing birds might be able to reclaim energy from the vortex sheet; Cone stated that the vortices may be producing a negative induced drag (i.e. thrust). In addition, the primary feathers may aid in drag reduction by spreading the vortex wake. This spreading would reduce drag, and indicates that the shape and strength of the vortex wake of a flapping bird may be significantly different from that of a fixed-wing aircraft of similar planform. Munk (1933) and others (Storer, 1948; Savile, 1957; Van Wormer, 1968, Lissaman and Shollenberger, 1970) proposed that linear formation flight may reduce induced drag. Each bird in the formation flies behind and slightly to the side of the bird ahead, in this position the bird could "pick up" the rising vortex from the bird ahead, and gain extra lift. Those species observed flying in linear for- 
mations are generally large, heavy water birds, such as geese, swans, cranes, pelicans, cormorants, flamingos, storks, herons, and some of the larger ducks (Austin,1961). As previously discussed, large birds may have energy demands during migrations which could be met only by increased aerodynamic efficiency. Since soaring per se is not commonly observed among the majority of these birds, formation flight and/or efficient use of prevailing winds could be energy-conserving mechanisms, particularly useful for long distances. Bent (1925) and Howley (1884) suggested that the characteristic Vee formation is utilized only for long distances. As will be discussed below, my personal observations concur with this suggestion.

If formation flight can reduce induced drag, then several factors must be considered. One such factor is equal distribution of drag. If a flock is to remain a unit, all birds should have equal drag savings; otherwise, some birds might be able to continue flight after others are ready to stop for rest. Lissaman and Shollenberger (1970) suggested that a Vee formation can give such equal distribution, so even the lead bird saves as much energy as the rest of the formation (they suggested that the lead bird receives upwash from the two birds behind). A weaker bird conceivably could fly in the center of the Vee (between the legs) and have even greater drag reduction, thus enabling it to maintain the speed of the rest of the flock. Lissaman and Shollenberger based their hypothetical model 
on the properties of a fixed-wing aircraft with the same geometry of an idealized formation-flying bird.

Another factor is the tip-to-tip spacing between birds (see Figure 1, distance C). If tip spacing is too wide, a bird could avoid the upwash fields from the birds on either side, and therefore have no drag savings. Lissaman and Shollenberger suggested that there would be significant drag savings only with small tip spacing; their suggested distance for a Vee formation was one-tenth the average span of the birds (for Canada Geese, approximately 12.5-15 cm.). According to Lissaman and Shollenberger, the angle of the Vee should also vary with tip spacing.

The actual distance (see distance A, Figure 1) between birds is another consideration. Poncy proposed that the angle of the Vee is determined by the relation between neck length and wing spread. He demonstrated with drawings of three hypothetical flocks: Avocets (Recurvirostra avosetta), with relatively short necks, close spacing between birds, and a very obtuse formation angle; Great Cormorants (Phalacrocorax carbo), with medium-long necks, increased spacing, and an angle which, although greater than $90^{\circ}$, is less obtuse than that of the Avocets; and Greater Flamingos (Phoenicopterus ruber), which have very long necks, even wider spacing, and a Vee angle of approximately $90^{\circ}$. Poncy suggested that these angles are a direct function of the length of the neck, the amount of room each bird requires to flap its wings, and the point at which each 


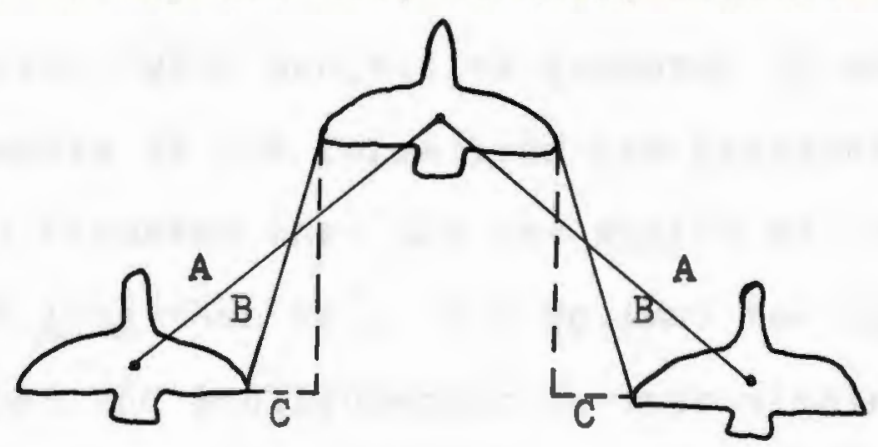

\section{FIGURE 1}

Hypothetical Vee formation, demonstrating possible distance measurements between two adjacent birds.

Distance $A=$ the distance from the center of mass of one bird to the center of mass of the following bird

Distance $B=$ the distance from the wing-tip of one bird to the wing-tip of the following bird

Distance $\mathrm{C}=$ the tip-to-tip spacing between two birds 
bird has a clear view of the birds ahead and the area in front. Poncy did not, however, measure these angles in the field, with projective geometry or other technique; the angles of his formations are hypothetical. Nachtigall (1970) reported that the Vee angles of formations are always less than $90^{\circ}$. The optimal Vee angle drawn by Lissaman and Shollenberger is approximately $110^{\circ}$ (this optimal angle is idealized, but Lissaman and Shollenberger stated that it is consistent with observed formations). There is a discrepancy among these data, further confused because these workers fail to describe the methods used to calculate observed formation angles. Accurate measurements of formations in flight are difficult to make without use of geometric relationships and/or sophisticated equipment: possibly these workers failed to consider depth perception and obliquity of view.

Nachtigall (1970) suggested that there should be wingbeat phase relationships among the birds in an exact Vee formation. He has demonstrated, through motion-picture analysis, that "the farther out along the arms of $a{ }^{\prime} \mathrm{V}$ ' the geese are located, the later their wings achieve a given stroke position"; and that these phase relationships are necessary if the birds are to employ the vortices for energy (Geyr von Schweppenburg, 1952, Nachtigall, 1970). Lissaman and Shollenberger disputed this theory, suggesting that such phase relationships are unnecessary. Their direct field observations indicated random phasing. 
The Vee formation is optimal for energy conservation, according to Lissaman and Shollenberger. They suggested that a formation of 25 birds could have up to $71 \%$ more range than a lone bird. This formation does not have to be symmetrical, if the birds position themselves for equal drag distribution. They also suggested that formations are more sensitive than lone birds to wind conditions, and that a tailwind will be of greatest advantage to a formation.

As Poncy (1941) suggested, formation flight might be a function of anatomical and behavioral parameters; he did not consider aerodynamic efficiency. Individual birds seem to have excellent means of reducing drag which man-made aircraft do not have available. Perhaps the vortex-wake of a flapping bird is not usable by another bird. On the other hand, the shape of linear formations may be a combination of visual aspects, individual distance, and aerodynamic efficiency. No one of these factors can be eliminated without further research. 


\section{MATERIALS AND METHODS}

\section{Data Acquisition}

Autumnal migrating flocks of Atlantic Canada Geese (Branta canadensis canadensis) were filmed at the Montezuma National Wildlife Refuge, Seneca Falls, New York, during the week of October 5-9, 1971. Early morning and late afternoon flocks were chosen for filming. Flocks were not filmed at random, but were chosen for several attributes, including distance from the observer and the height of the flock above the horizon. A third parameter was the type of formation, e.g. if a situation arose in which two flocks were visible at the same time, one of them a cluster and the other a Vee, the Vee would be filmed.

The vantage point from which the birds were filmed was a dike between two ponds. Since the birds were able to see anything on the dike, they avoided flying directly overhead.

Motion picture films were taken with a Beaulieu $40082 \mathrm{M}$ Super $8 \mathrm{~mm}$ Cine camera, at 18 frames per second and variable shutter open. The extension of the 8-64mm fl.9 Angenieux zoom lens depended upon the distance from the camera of the flock being filmed; in most cases a $64 \mathrm{~mm}$ focal length was necessary, but there were some flocks which flew close enough to the camera position that the complete zoom exten- 
sion would not have included the entire flock. In these cases, the zoom was returned to a point where the entire flock was visible. Kodachrome 11 Super $8 \mathrm{~mm}$ (ASA 25) film was used.

The information recorded for each take consisted of the date, time, location, roll number, take number, temperature $\left({ }^{\circ} \mathrm{C}\right)$, wind speed and direction, the direction from which the flock was flying, the direction toward which the flock was flying, and the maximum angle of the optical axis of the camera above the horizon (the elevation angle) as the flock was followed. Directions of the wind and flocks were obtained with a Silva (Type 1) compass: wind speed was determined with a pocket anemometer. If a flock flew over and landed in the near-by fields, filming would stop when the birds stopped flapping their wings and began to glide. Filming of a particular flock would usually start when a flock was obviously heading in or near the direction of the camera, and when the individual birds were visible through the fully-extended telephoto lens. Likewise, filming would stop when the flock was no longer clear as a group of individual birds.

The most important measurement was that of the angle of the optical axis of the camera lens above the horizon in relation to the position of a particular flock. By using this angle the true angle between the legs of a Vee or Jay formation could be determined. The apparent angle of a formation appears to change as the formation flies 


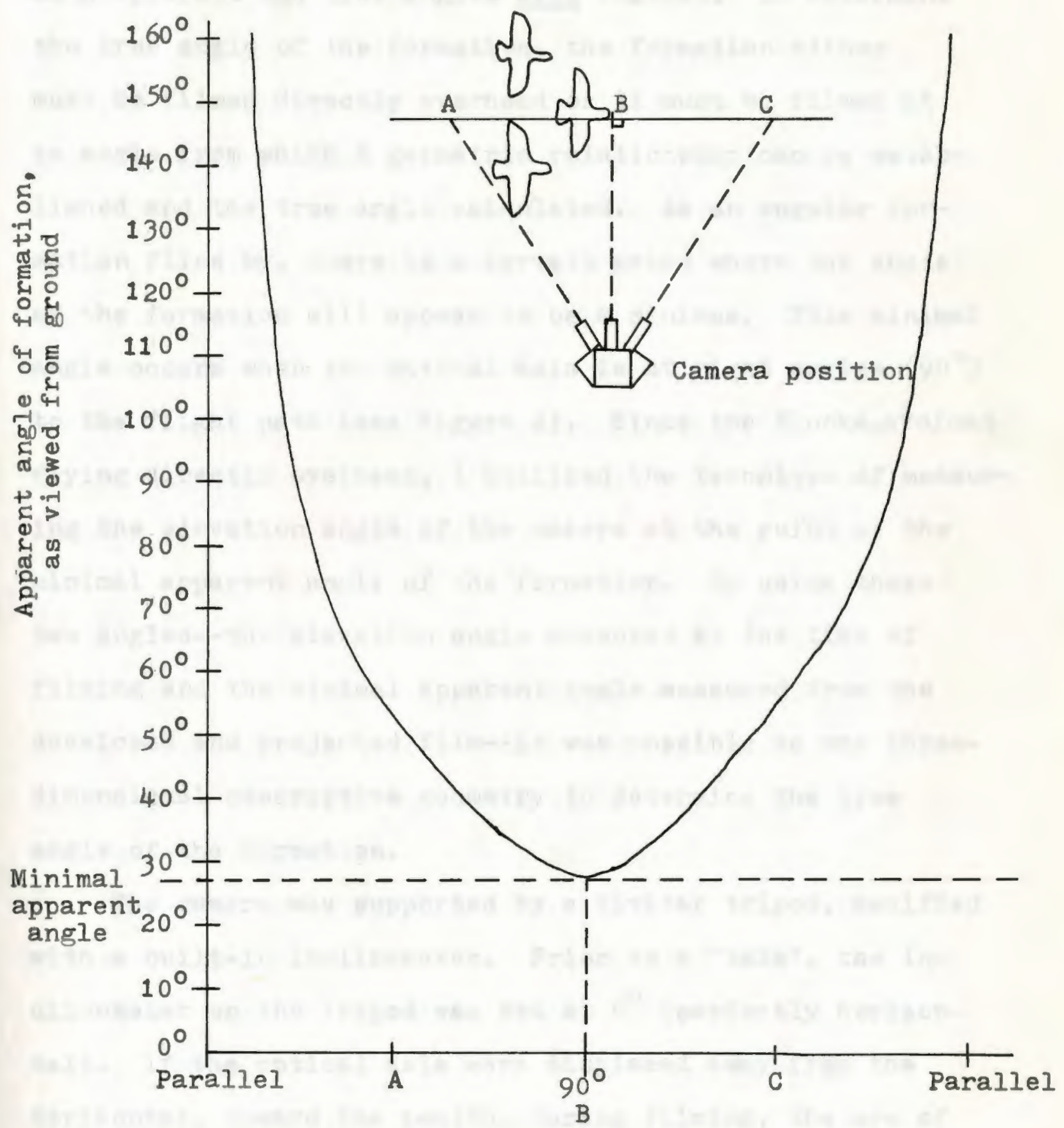

Horizontal angle of optical axis of camera in relation to flight path of formation

\section{FIGURE 2}

Change in apparent angle of a formation

in relation to the angle of the

optical axis of camera 
through the air, even though the birds maintain their positions within the flock (if they change their positions, both apparent and true angles will change). To determine the true angle of the formation, the formation either must be filmed directly overhead or it must be filmed at an angle from which a geometric relationship can be established and the true angle calculated. As an angular formation flies by, there is a certain point where the angle of the formation will appear to be a minimum. This minimal angle occurs when the optical axis is at right angles $\left(90^{\circ}\right.$ ) to the flight path (see Figure 2). Since the flocks avoided flying directly overhead, I utilized the technique of measuring the elevation angle of the camera at the point of the minimal apparent angle of the formation. By using these two angles--the elevation angle measured at the time of filming and the minimal apparent angle measured from the developed and projected film--it was possible to use threedimensional descriptive geometry to determine the true angle of the formation.

The camera was supported by a Vivitar tripod, modified with a built-in inclinometer. Prior to a "take", the inclinometer on the tripod was set at $0^{\circ}$ (perfectly horizontal). If the optical axis were displaced away from the horizontal, toward the zenith, during filming, the arm of the inclinometer was also displaced vertically, so that at the end of a take it was possible to measure the greatest angle of displacement. For example, if the camera had 
been tilted, at some point during the take, to $45^{\circ}$ from the horizontal, then at the end of the take the camera could be returned to the point of greatest displacement, as recorded by the tripod inclinometer (here, $45^{\circ}$ ), and the angle measured with a portable inclinometer (see Figure 3). This maximum elevation angle (degrees of displacement) corresponds to the point at which the apparent flock angle is minimal. An elevation angle was recorded for all takes, regardless of the type of flock being filmed. Meteorological data taken at the time of filming was confirmed by the Environmental Data Service (Local Climatological Data) published by the U. S. Department of Commerce.

\section{Data Analysis}

Fifteen rolls of film (750 feet) were developed by Kodak. A Kodak MFS-8 motion analysis projector, allowing frame by frame analysis, was used for film analysis; the film was projected onto an 8" $\times 11 "$ screen.

The films were first analyzed for types of formations and the number of birds in each formation. These results were then correlated with wind conditions and time of day. Angular formations were studied and further analyzed if they met the following requirements:

(1) the formation was clearly visible as a group of individual birds, not just as shapes silhouetted against the sky, 


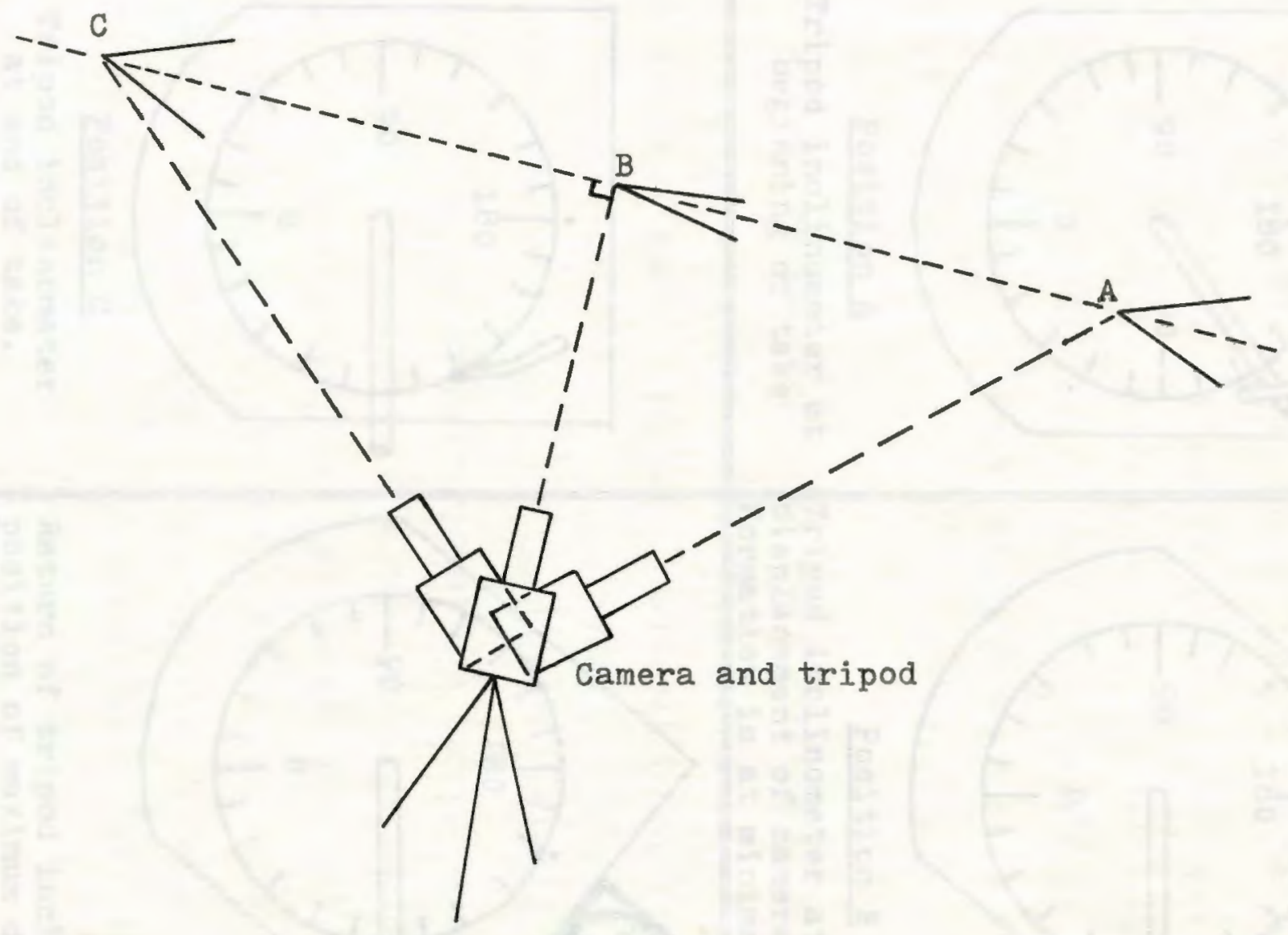

FIGURE 3a

Change in apparent angle of a formation along the flight path of the formation, as viewed from the ground. B represents the minimal apparent angle. 


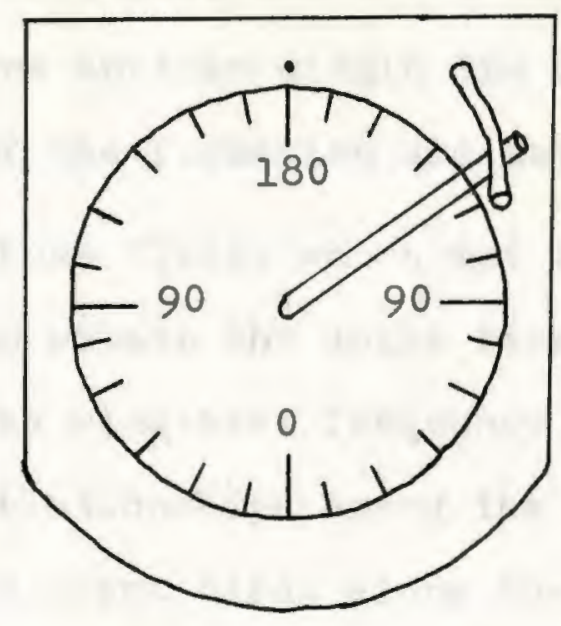

Position A

Tripod inclinometer at beginning of take

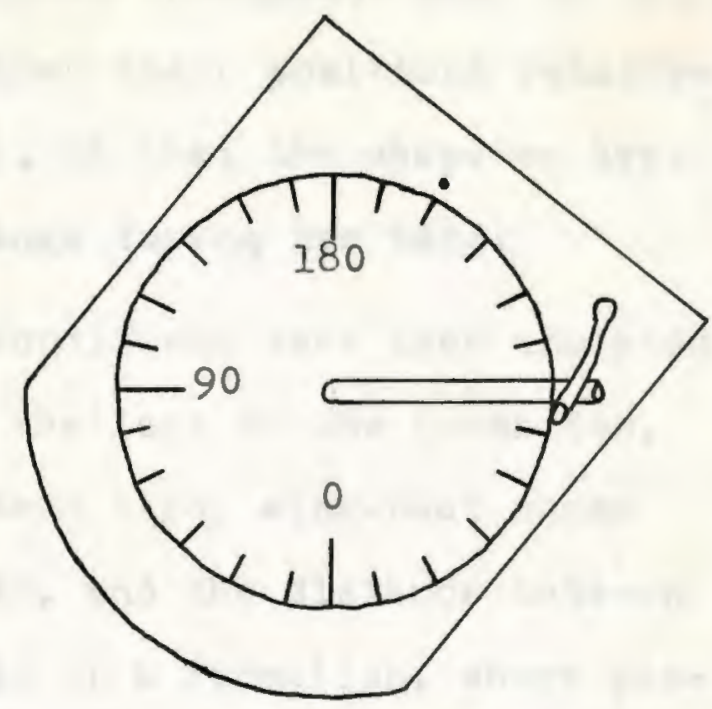

Position B

Tripod inclinometer at point of maximum displacement of camera optical axis. Formation is at minimal apparent angle.

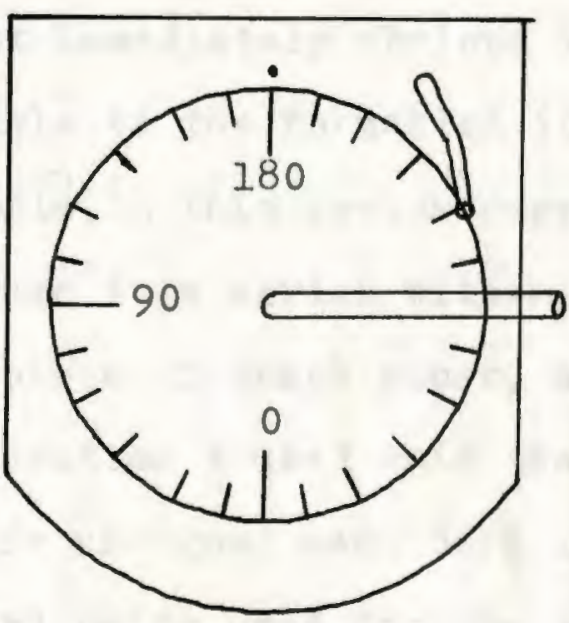

Position C

Tripod inclinometer at end of take.

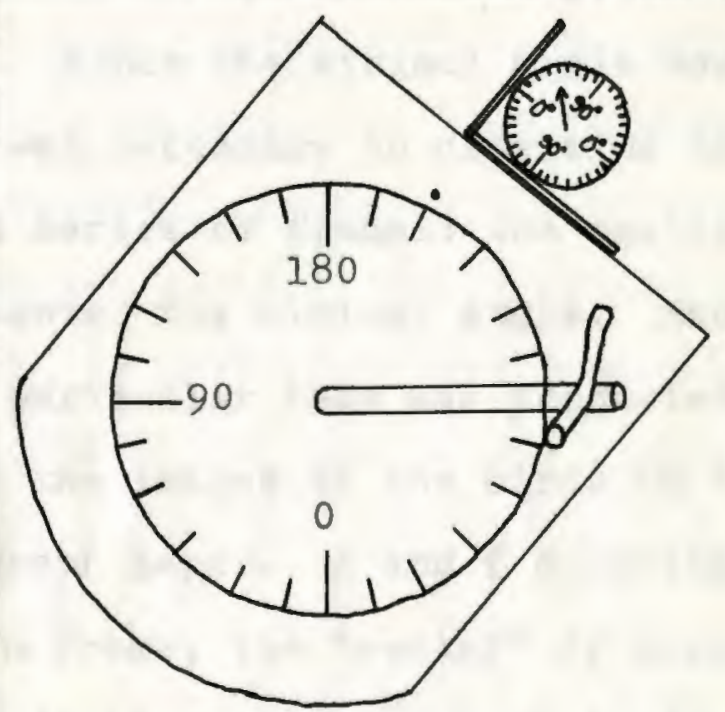

Return of tripod inclinometer to position of maximum displacement (B) + measurement of the elevation angle with portable inclinometer.

\section{FIGURE 3b}

Measurement of vertical displacement of camera optical axis (the elevation angle) using the tripod inclinometer. Positions $A, B, \& C$ correspond to the camera positions $A, B$, and $C$ in Figure $3 a$. 
(2) the formation persisted throughout most of the take, i.e. the birds maintained their positions relative to one another within the flock, so that the shape or type of the formation did not change during the take.

Those flocks which met the conditions were then analyzed to obtain the angle between the legs of the formation, the wing-beat frequency of each bird, wing-beat phase relationships among the birds, and the distance between adjacent birds along the legs of a formation, where possible.

To obtain the true angle of a formation it was first necessary to determine which frame of the take represented the minimal apparent angle. Since the minimal angle was not immediately obvious it was necessary to determine the angle of the formation in a series of frames; the smallest angle in this series represented the minimal angle. Each frame in a series within a particular take was projected on a piece of graph paper, and the images of the birds in the formation traced onto the graph paper. $X$ and $Y$ coordinates were assigned each bird in a frame, the "center" of each bird being used for the coordinate point. Due to limitations in the resolution of the Super $8 \mathrm{~mm}$ film, and to perspective, this "center" point was the only point on the birds which could be used consistently for all formations. The center was estimated as being the center of the mass of each bird, between its wings. In addition, each bird was numbered, the lead bird as No. 1, the bird immediately 
behind No. 1 and seemingly nearest the observer, as No. 2, etc. Those birds in the leg of the formation which appeared farther from the observer were numbered as No. $2^{\prime}$, No. $3^{\prime}$, following the convention of Nachtigall (1970). After assigning coordinates, a linear regression was run on each leg of a formation, using a Monroe 1785, Electronic Programmable Printing Calculator. Once the regression analysis was completed I measured the angle of the formation.

I converted the minimal apparent angle between the legs of the formation, obtained from the regression analysis, to the true angle of the formation. This step used projective geometry (three-dimensional descriptive geometry). Figure 4 (a-e) illustrates how the minimal apparent angle is projected upon the camera elevation, and then projected as the true angle of the formation (Slaby, 1966). Figure $4 a$ depicts the angle of a formation determined from regression analysis. The shape and size of this angle are represented exactly as they appeared on the film frame of the minimal apparent angle. Point $A$ represents the apex of the Vee: a indicates the angle of the Vee, in this case $12^{\circ}$. In Figure $4 \mathrm{~b}$, line $X Y$ represents the horizontal plane upon which the camera-tripod apparatus stood, i.e. the ground. The distance from angle a to line $X Y$ is irrelevant, as this distance is not intended to represent a true (relative) distance between the observer and the Vee formation. The minimal apparent angle was filmed at the camera elevation angle $\beta$ (here, $\beta=30^{\circ}$ ). Figure $4 \mathrm{c}$ illustrates angle $\beta$, 
which is formed by lines XY (the ground) and XZ (the elevation edge). To project angle $\alpha$ so that the true shape and angle of the formation can be determined, a line is drawn from point $A$ parallel to line $X Y$ and intersecting line $X Z$ at point $A^{\prime}$. Figure $4 \mathrm{C}$ shows line $\mathrm{AA}^{*}$ relative to the elevation edge $(x 2)$. In projecting angle $\alpha$, at least 3 points must be projected onto the elevation edge. Point $A^{*}$ has already been projected onto the elevation edge; two more points are needed. In Figure $4 \mathrm{~d}, \mathrm{a}$ line is drawn through angle $\alpha$ perpendicular to line $\mathrm{AA}^{*}$ and intersecting both legs of the formation. The distance of this line from the apex of the Vee (point A) is irrelevant as long as the line remains perpendicular to $\mathrm{AA}^{\prime}$ and intersects both Vee legs. The point at which this line intersects the Vee leg nearest line $\mathrm{XY}$, intersects line $\mathrm{AA}^{\prime}$, and intersects the Vee leg farthest from line $X Y$, are labelled $B, D$, and $C$, respectively. A line is extended from point $B$ to line $X Z$, perpendicular to line $B C$, and from point $C$ to $X 2$, perpendicular to $B C$. Three points $\left(B^{\circ}, A^{*}\right.$, and $\left.C^{\bullet}\right)$ have been projected onto the elevation edge; each of these points represents a point on the angle of the Vee formation (see Figure 4d).

To obtain the true angle, points $A^{\prime}, B^{\prime}$, and $C^{\prime}$ must be projected to form an angle. Figure $4 \mathrm{e}$ illustrates this final step. A line is drawn from point $A^{\prime}$, perpendicular to line XZ. The length of line $A D$ is then projected onto the line drawn from $A^{\prime} ;$ this line is labelled $A^{\circ} A^{\prime \prime}$. Lines are drawn connecting $B^{\prime}$ to $A^{\prime \prime}$ and $C^{\prime}$ to $A^{\prime \prime}$. The angle thus 


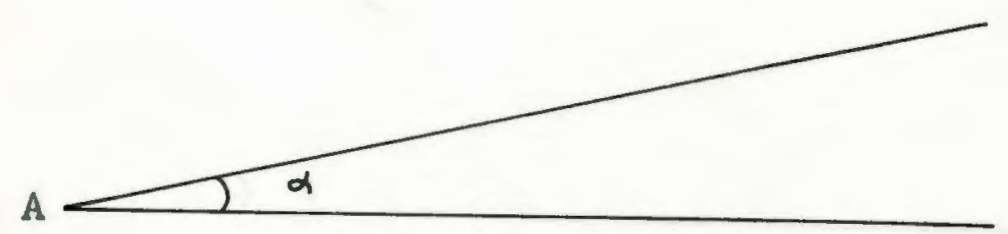

\section{FIGURE $4 a$}

First step in the conversion of the minimal apparent angle of a formation to the true angle. Angle $\alpha$

represents the minimal apparent angle, determined by regression analysis: the shape and size of this angle are drawn exactly as they appeared in the film frame of the minimal apparent angle. Here, $\alpha=12$. 


\section{FIGURE $4 \mathrm{~b}$}

2nd. step in the conversion of the minimal apparent angle. Line XY represents the horizontal plane (the ground) from which the formation (angle $\alpha$ ) was observed. 


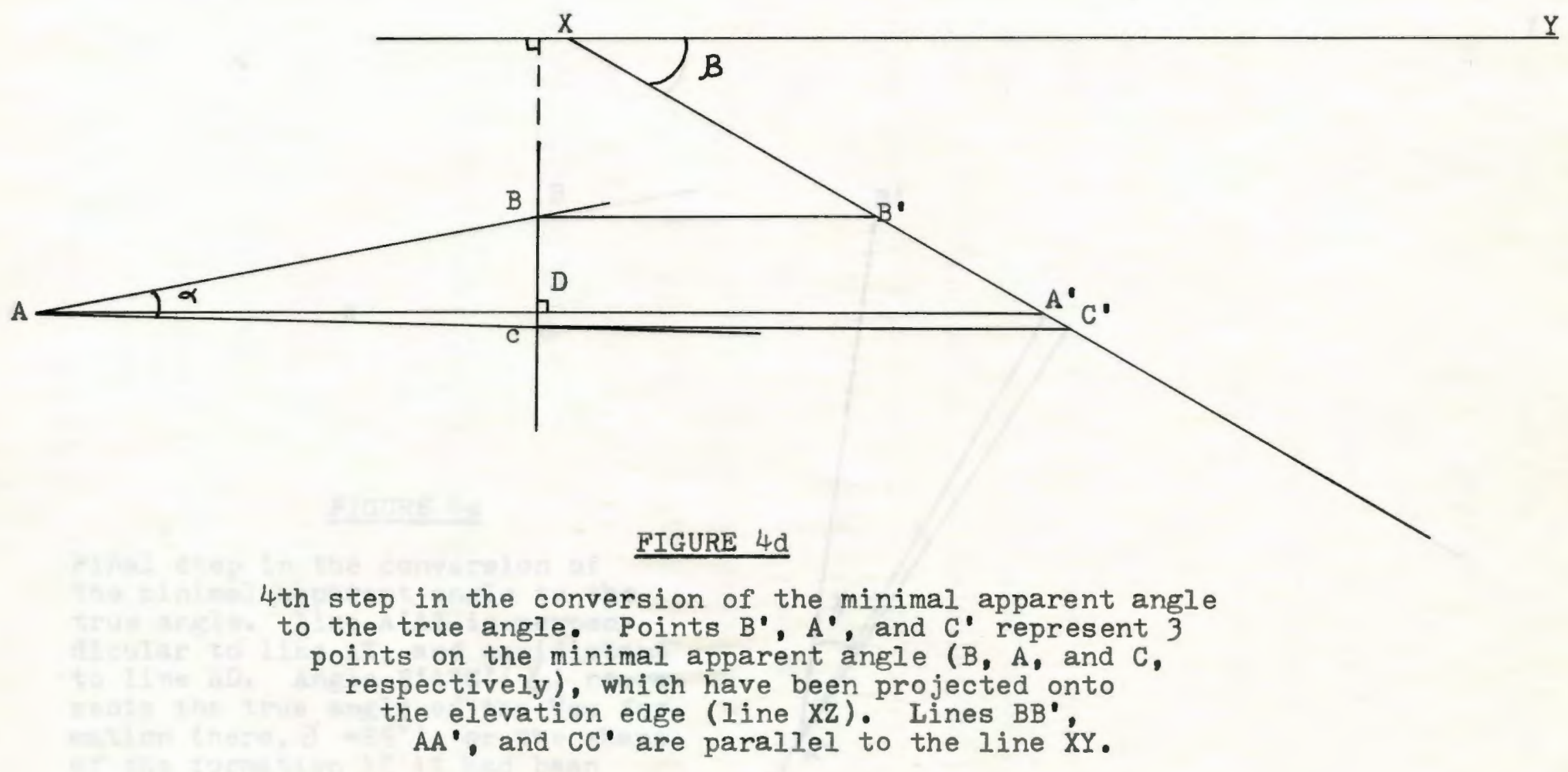




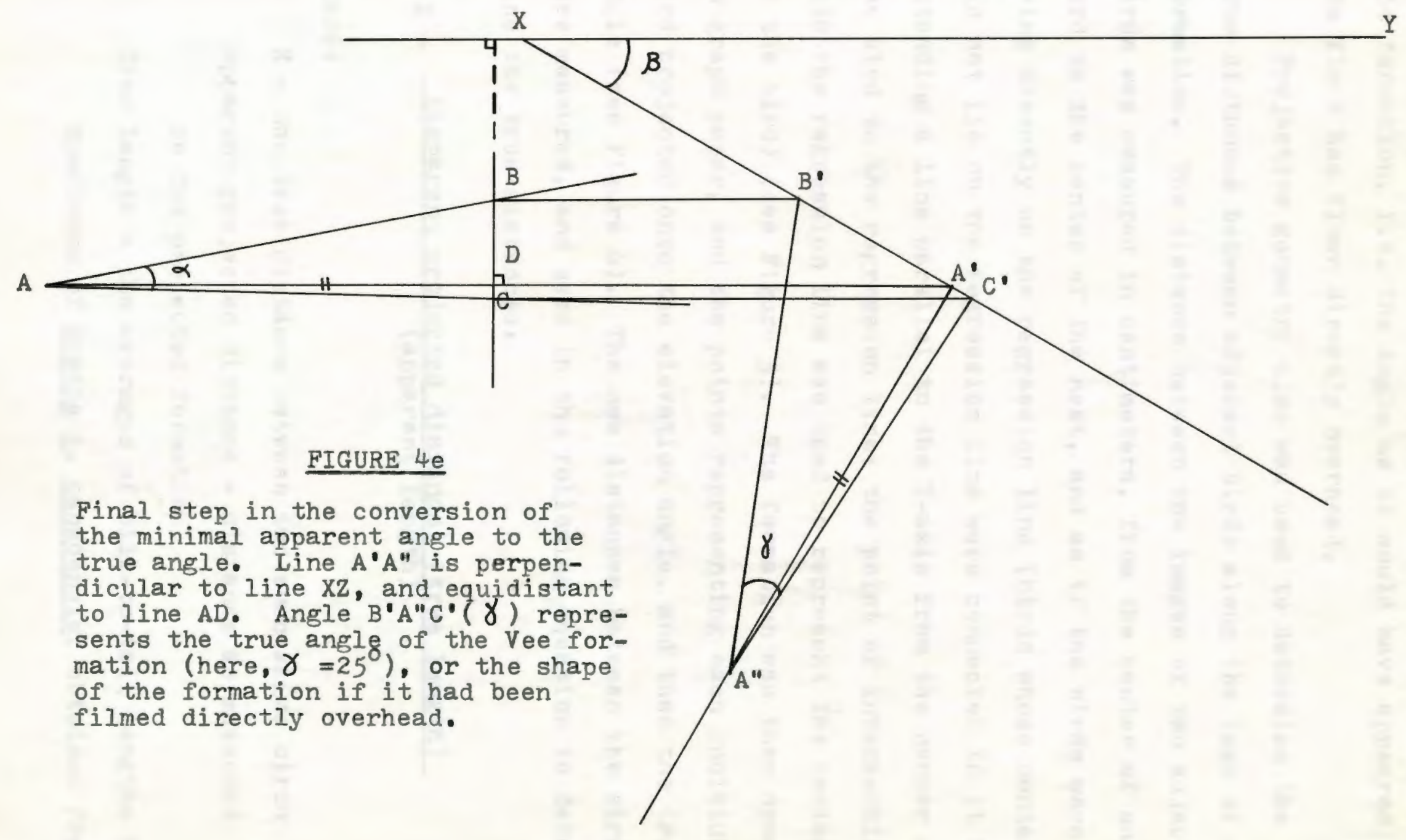


formed (angle $B^{\prime} A^{\prime \prime} C^{\bullet}$, or $\gamma$ ) represents the true angle of the formation, i.e. the angle as it would have appeared if the flock had flown directly overhead.

Projective geometry also was used to determine the true distances between adjacent birds along the legs of a formation. The distance between the images of two adjacent birds was measured in centimeters, from the center of one bird to the center of the next, and as if the birds were lying directly on the regression line (birds whose centers did not lie on the regression line were connected to it by extending a line parallel to the $Y$-axis from the center of the bird to the regression line; the point of intersection with the regression line was used to represent the center of the bird) (see Figure 5). The formation was then drawn on graph paper, and the points representing each individual bird projected onto the elevation angle, and then the true angle (see Figure 6). The new distances between the birds were measured, and used in the following equation to determine the true distances:

$$
X=\frac{\text { (apparent projected distance) (true length) }}{\text { (apparent length) }}
$$

where:

$\mathrm{X}=$ the true distance between two successive birds Apparent projected distance $=$ distance as measured on the projected formation

True length $=$ the averages of bill-to-tail lengths of specimens of Branta c. canadensis, obtained from 


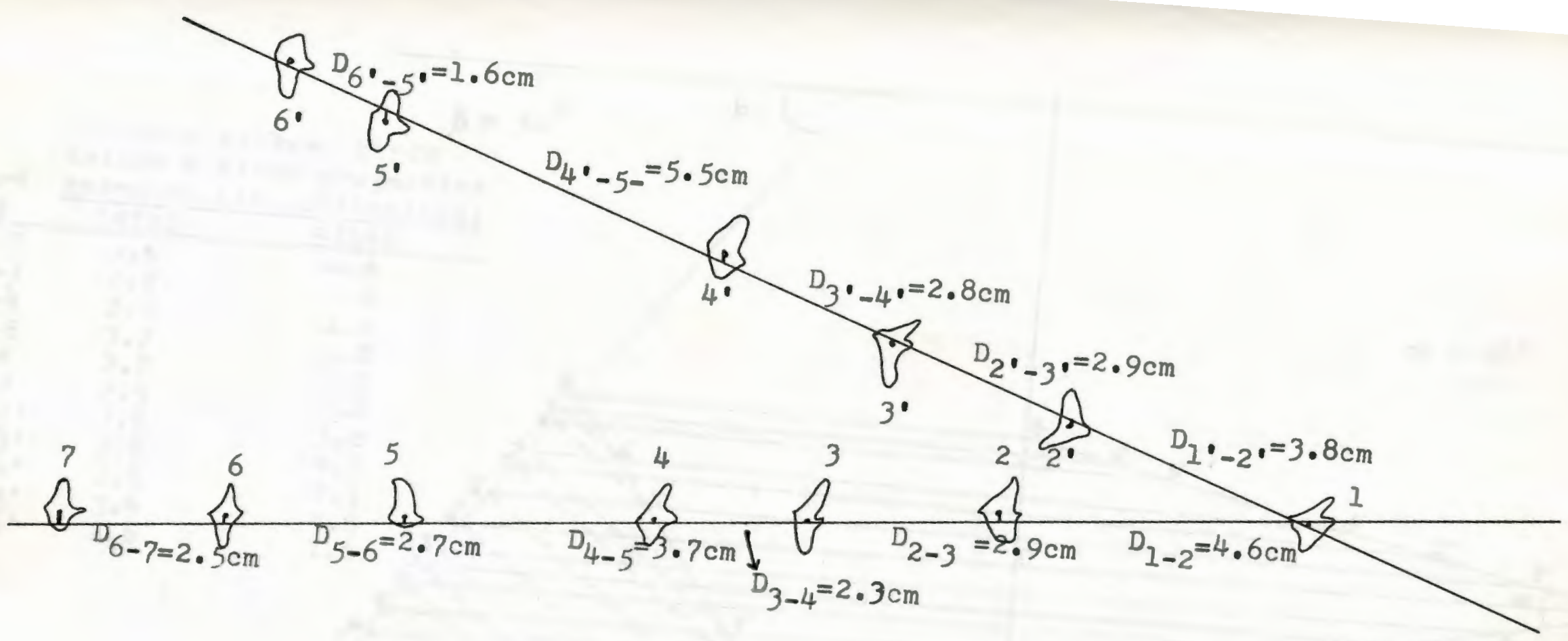

\section{EIGURE 5}

Measurement of distance between the legs of a Vee formation en adjacent birds along jected fil formation traced direct minimal apparjected film frame)( $D=$ Distance) 


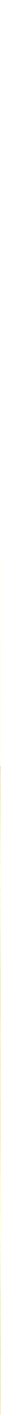

(Scale of formation $=\frac{1}{2}$ distance in Figure 5$)$ 
the published data of Ruthven and Zimmerman (1965), Terres (1968), and the field work of George Bond (unpublished data). This value was $85.2 \mathrm{~cm}$., and was used as a constant for all formations studied in this project.

Apparent length $=$ the average of the bill-to-tail

lengths, for the birds in a particular leg of a formation, as they appeared on the film frame depicting the minimal angle.

Wing-beat frequency was analyzed by marking the wing position of each bird in a formation, for several frames, to determine the number of frames for completion of a wing beat, hence beats/second. Four wing positions were described and assigned letters as follows:
$A=$ maximal extension of the wings during the upstroke
$B=$ maximal bending of the wings during the upstroke
$\mathrm{C}=$ extension of the wings on a horizontal plane, dur- ing the downstroke
$D=$ maximal extension of the wings on a vertical plane, during the downstroke.

Therefore, a sequence depicting one complete wing beat would read $B, A, C, D, B$, etc. Each bird in a frame was given a letter representing its wing position; approximately 20 frames per formation were analyzed, and an average wing-beat frequency for each bird calculated. Phase relationships were studied from the same data. 


\section{$\underline{\text { RESULTS }}$}

The number of different formation types and the average number of birds in each formation type are shown in Table 1. A total of 104 flocks were counted; of the 104 flocks, 41 (39.4\%) were column/echelon formation and 41 (39.4\%) were "angular" formations (Vee, Jay, Compound Vee, Inverted Jay). The mean number of birds in each type of formation was calculated for those flocks containing fewer than 100 birds; in those flocks of greater than 100 birds, counting became inaccurate due to the distance of the birds and the poor resolution of the film, hence such flocks were categorized separately in Table 1. The overall mean number of birds per flock, excluding those flocks of more than 100 birds, was 27 birds/flock.

Table 2 lists the types of formations seen at sunrise and sunset, and under various wind conditions. The types of formations observed at dawn and sunset did not vary significantly, but the size of the flocks differed. The average flock size at dawn was 27 birds, at sunset 21 birds. All but two of the flocks numbering over 100 birds appeared at dawn.

Weather conditions varied slightly during the week of filming. The temperature ranged from $3.6^{\circ} \mathrm{C}$ to $23.5^{\circ} \mathrm{C}$ during the week. The average temperature at dawn was $9.4{ }^{\circ} \mathrm{C}$, 
TABLE 1

Types of formations and numbers of birds in each formation type

\begin{tabular}{|c|c|c|c|c|c|c|}
\hline $\begin{array}{l}\text { Formation } \\
\text { Type } \\
\end{array}$ & $\begin{array}{c}\text { Number of formation } \\
\text { type counted }\end{array}$ & $\begin{array}{l}\% \text { of } \\
\text { Total } \\
\end{array}$ & Mean & $\begin{array}{l}\text { Number of Birds } \\
\text { per Flock }\end{array}$ & $\begin{array}{l}\text { Range in Number } \\
\text { of Birds }\end{array}$ & $\begin{array}{l}\text { Number of flocks with } \\
\text { more than } 100 \text { Birds }\end{array}$ \\
\hline $\begin{array}{l}\text { Column/ } \\
\text { Echelon }\end{array}$ & 41 & $39.4 \%$ & & 21.8 & 3 to 80 & 4 \\
\hline Vee & $1 ?$ & $16.4 \%$ & & 21.6 & 7 to 47 & 1 \\
\hline Jay & 16 & $15.4 \%$ & & 27.9 & 7 to 70 & 2 \\
\hline $\begin{array}{l}\text { Compound } \\
\text { Vee }\end{array}$ & 6 & $5.8 \%$ & & 60.0 & 47 to 80 & 3 \\
\hline Cluster & 18 & $17 \cdot 3 \%$ & & 17.9 & 7 to 53 & 2 \\
\hline $\begin{array}{l}\text { Inverted } \\
\text { Jay }\end{array}$ & 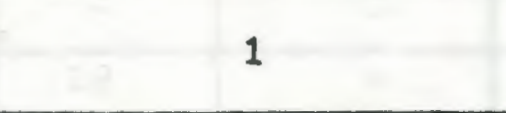 & $.96 \%$ & & $(22)^{3}$ & ------ & 0 \\
\hline Front & 4 & $3.8 \%$ & & 21.8 & 8 to 32 & 0 \\
\hline $\begin{array}{l}\text { Vee with } \\
\text { birds inside }\end{array}$ & $=$ & $.96 \%$ & & $(25)^{3}$ & $---\infty-n-$ & 0 \\
\hline $\mathrm{T}$ & 104 flocks & $100 \%$ & & $x=27.2$ & & \\
\hline
\end{tabular}




\section{TABLE 2}

Relationship of time of day and observed flocks, and relationship of wind conditions and numbers of flocks

\begin{tabular}{|c|c|c|c|c|c|c|c|c|}
\hline \multirow{4}{*}{$\begin{array}{l}\text { Type } \\
\text { of } \\
\text { Formation }\end{array}$} & \multirow{3}{*}{\multicolumn{2}{|c|}{$\begin{array}{c}\text { Number of flocks } \\
\text { of formation type } \\
\text { observed }\end{array}$}} & \multicolumn{6}{|c|}{$\begin{array}{l}\text { Number of flocks of formation type observed under particular wind } \\
\text { speeds, and direction of flocks in relation to direction of wind }\end{array}$} \\
\hline & & & \multicolumn{3}{|c|}{$0-9 \mathrm{kph}$} & \multicolumn{3}{|c|}{$10-18 \mathrm{kph}$} \\
\hline & & & & Flying wi & & & Flying wit & \\
\hline & Dawn & Sunset & Tailwind & Headwind & Crosswind & Tailwind & \begin{tabular}{|l|} 
Headwind \\
\end{tabular} & Crosswind \\
\hline $\begin{array}{l}\text { Column/ } \\
\text { Echelon }\end{array}$ & 24 & 17 & $\begin{array}{l}10 \\
(9.6 \%)\end{array}$ & 0 & $(12 \cdot 5 \%)$ & $(1.9 \%)$ & 0 & $\begin{array}{l}10 \\
(9.6 \%)\end{array}$ \\
\hline Vee & 8 & 9 & $(3.8 \%)$ & 0 & $(6.7 \%)$ & 0 & 0 & $(2.9 \%)$ \\
\hline Jay & 6 & 10 & $(4.8 \%)$ & $(.96 \%)$ & $(3.8 \%)$ & 0 & 0 & $(2.9 \%)$ \\
\hline $\begin{array}{l}\text { Compound } \\
\text { Vee }\end{array}$ & 2 & 5 & $(1.9 \%)$ & 0 & $(3.8 \%)$ & 0 & 0 & 0 \\
\hline Cluster & 12 & 4 & $(1.9 \%)$ & 0 & $(4.8 \%)$ & $(.96 \%)$ & 0 & $(3.8 \%)$ \\
\hline $\begin{array}{l}\text { Inverted } \\
\text { Jay }\end{array}$ & 1 & 0 & 0 & 0 & $\begin{array}{c}1 \\
(0.96 \%)\end{array}$ & 0 & 0 & 0 \\
\hline Front & 4 & 1 & 0 & 0 & $\begin{array}{c}4 \\
(3.8 \%) \\
\end{array}$ & 0 & 0 & 0 \\
\hline $\begin{array}{l}\text { Vee with } \\
\text { birds inside }\end{array}$ & 1 & 0 & 0 & 0 & 0 & 0 & 0 & 0 \\
\hline Total & $\begin{array}{c}58 \\
(55.8 \%)\end{array}$ & $\begin{array}{c}46 \\
(44.2 \%)\end{array}$ & $\begin{array}{c}23 \\
22.1 \%)\end{array}$ & $(0.96 \%)$ & $\begin{array}{c}38 \\
(36.5 \%)\end{array}$ & $(2.9 \%)$ & 0 & $\begin{array}{c}20 \\
(19.2 \%)\end{array}$ \\
\hline
\end{tabular}


TABLE 2 - continued

\begin{tabular}{|c|c|c|c|c|c|c|}
\hline \multirow{4}{*}{$\begin{array}{c}\text { Type } \\
\text { of } \\
\text { Formation }\end{array}$} & \multicolumn{6}{|c|}{$\begin{array}{l}\text { Number of flocks of formation type observed under particular wind } \\
\text { speeds, and direction of flocks in relation to direction of wind }\end{array}$} \\
\hline & \multicolumn{3}{|c|}{$19-35 \mathrm{kph}$} & \multicolumn{3}{|c|}{$36-44 \mathrm{kph}$} \\
\hline & \multicolumn{3}{|c|}{ Flying with } & \multicolumn{3}{|c|}{ Fiying with } \\
\hline & Tailwind & Headwind & Crosswind & Tailwind & Headwind & Crosswind \\
\hline $\begin{array}{l}\text { Column/ } \\
\text { Echelon }\end{array}$ & 0 & 0 & $(4.8 \%)$ & 0 & 0 & $(0.96 \%)$ \\
\hline Vee & 0 & 0 & $(2.9 \%)$ & $\overline{0}$ & 0 & 0 \\
\hline Jay & 0 & 0 & $(2.9 \%)$ & 0 & 0 & 0 \\
\hline $\begin{array}{l}\text { Compound } \\
\text { Vee }\end{array}$ & $\overline{0}$ & 0 & $(0.96 \%)$ & 0 & 0 & 0 \\
\hline Cluster & $\overline{0}$ & $\overline{0}$ & $(3.8 \%)$ & $\overline{0}$ & $\overline{0}$ & $\overline{0}$ \\
\hline $\begin{array}{l}\text { Inverted } \\
\text { Jay }\end{array}$ & 0 & 0 & 0 & 0 & 0 & 0 \\
\hline Front & 0 & 0 & $(0.96 \%)$ & 0 & 0 & 0 \\
\hline $\begin{array}{l}\text { Vee with } \\
\text { birds inside }\end{array}$ & 0 & 0 & $\begin{array}{c}1 \\
(0.96 \%) \\
\end{array}$ & 0 & 0 & 0 \\
\hline & 0 & 0 & $\left(1 \frac{18}{(7 \cdot 3 \%)}\right.$ & 0 & 0 & $(0.96 \%)$ \\
\hline
\end{tabular}


at sunset $17.4^{\circ} \mathrm{C}$. The wind speed varied from $0 \mathrm{kph}$ to $39 \mathrm{kph}$, the average wind speed at dawn being $7.2 \mathrm{kph}$, and at sunset, $14.8 \mathrm{kph}$ (range from $0 \mathrm{kph}$ to $39 \mathrm{kph}$ ). Wind direction varied from southeast to northwest, the prevailing winds being westerly.

Of the flocks counted, approximately $60 \%$ were filmed in 0-9 kph winds, $22 \%$ in 10-18 kph winds, 17\% in 19-35 kph winds, and $1 \%$ in winds over $35 \mathrm{kph}$. $74 \%$ of the flocks flew with a crosswind, $25 \%$ with a tailwind (flight path within $45^{\circ}$ of wind destination) and $1 \%$ into a headwind (flight path within $45^{\circ}$ of wind source) (after Tucker and Schmidt-Koenig, 1971).

of the 34 Vee and Jay formations filmed, only five met the criteria for further analysis; the majority of the flocks were disqualified because of lack of persistence of the formation, i.e. the birds within the formations changed positions frequently, so that the angles were also changing. The true angle was determined for the five formations, but of these five, only three could be used to determine the distances between adjacent birds; problems of perspective and distance of the flock from the camera made two of the flocks unusable. Poor resolution of the Super $8 \mathrm{~mm}$ film also eliminated two flocks in the analysis of wing-beat frequency and phase relationship.

Figures 7 through 11 (formations $A-E$ ) show the five formations, each drawn directly from the film frame of the minimal apparent angle. The outlines of the birds are 
more definite in formations $B, C$, and $D$, than in $A$ and $E$; again, this is due to the poor resolution of the Super $8 \mathrm{~mm}$ film. The lines drawn through the legs of each formation represent the calculated regression lines; the minimal angle formed by these regressions is given for each formation, as is the camera elevation angle and the true angle, determined by descriptive geometry. Also shown in these figures is the relationship of the flock direction to wind direction and speed. All flocks were filmed in winds of $10 \mathrm{kph}$ or less, and all but formation A flew with a tailwind.

Table 3 shows the true distances between adjacent birds along the legs of the formations, computed as described above. The overall mean distance between birds was 4.1 meters $\left(S . D_{0}=0.88 \mathrm{~m} \cdot\right)$; the distance ranged from $12.8 \mathrm{~m}$. to $2.5 \mathrm{~m}$.

Table 4 shows the wing-beat frequencies for each bird in formations $B, C$, and $D$. The frequencies differed very slightly among the formations. The overall mean frequency was 4.6 frames/wing-beat, or 4 beats/second. There was no evidence for phase relationships among the birds in a leg of any formation studied. 


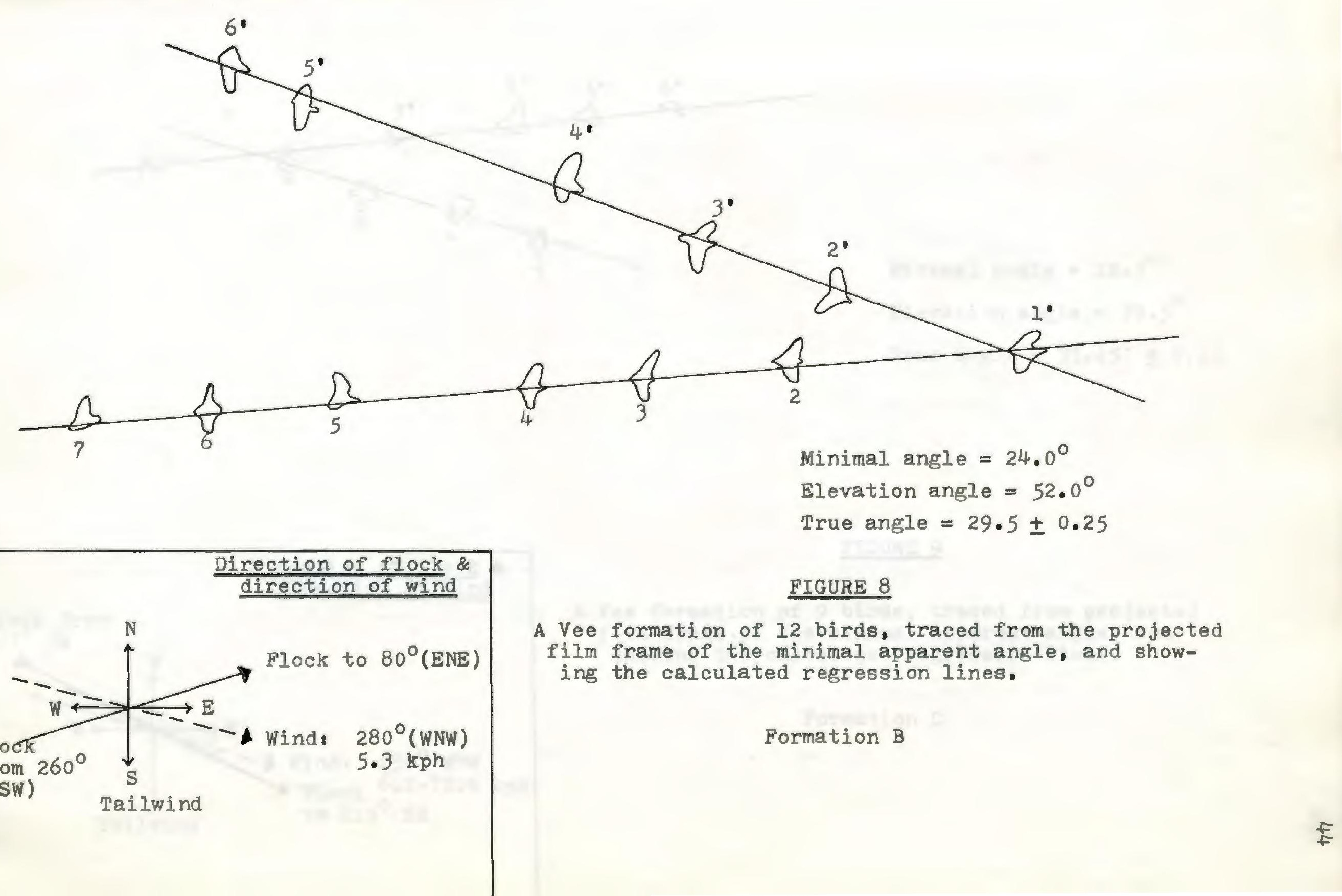




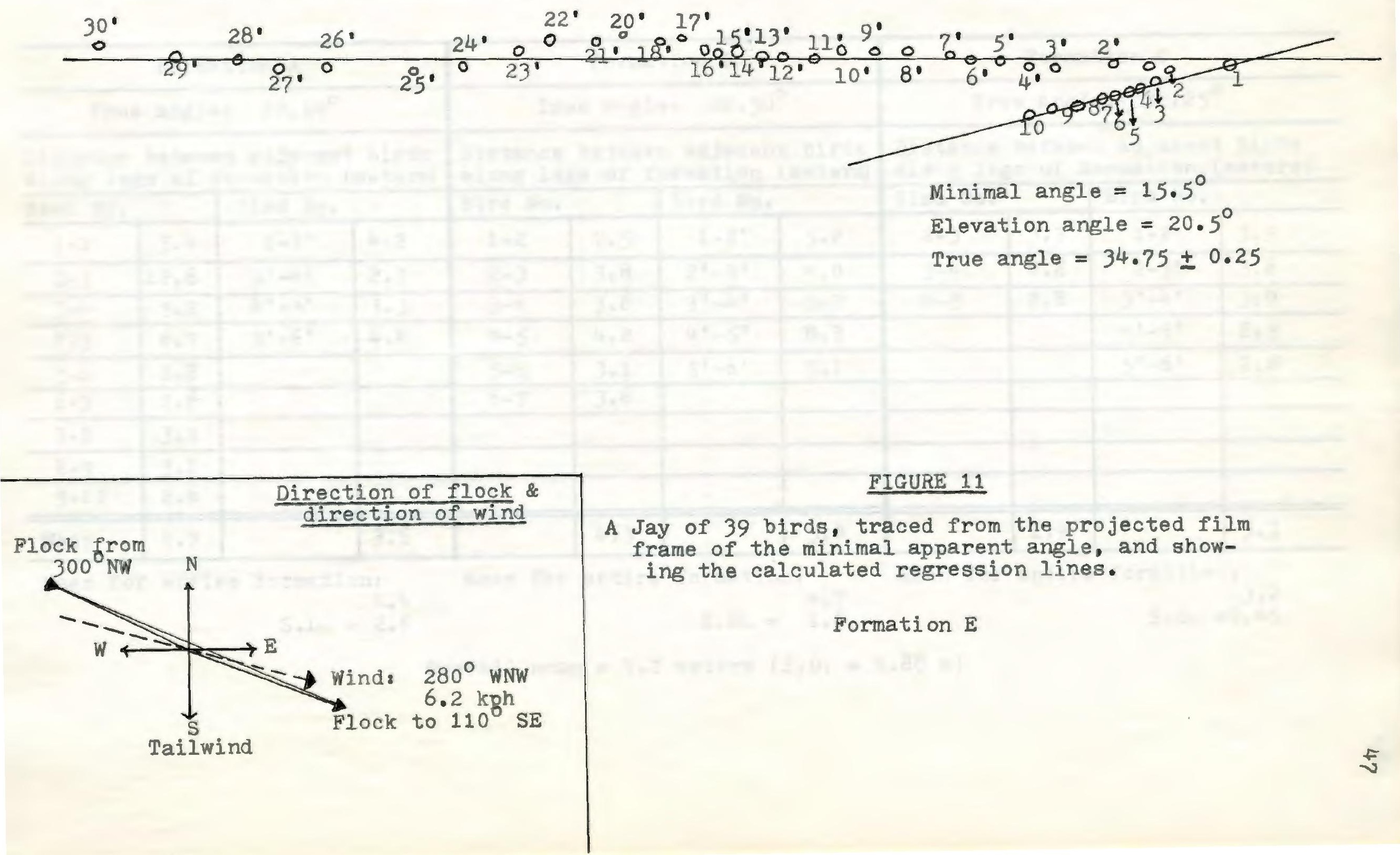


TABLE 3

Distances between adjacent birds along the legs of a formation

\begin{tabular}{|c|c|c|c|c|c|c|c|c|c|c|c|}
\hline \multicolumn{4}{|c|}{ Formation A } & \multicolumn{4}{|c|}{ Formation $B$} & \multicolumn{4}{|c|}{ Formation $\mathrm{C}$} \\
\hline \multicolumn{2}{|c|}{ True an } & \multicolumn{2}{|c|}{$27 \cdot 50^{\circ}$} & \multicolumn{4}{|c|}{ True angle: $29.50^{\circ}$} & \multicolumn{4}{|c|}{ True angle: $32.25^{\circ}$} \\
\hline \multicolumn{4}{|c|}{$\begin{array}{l}\text { Distance between adjacent birds } \\
\text { along legs of formation (meters) }\end{array}$} & \multicolumn{4}{|c|}{$\begin{array}{l}\text { Distance between adjacent birds } \\
\text { along legs of formation (meters) }\end{array}$} & \multicolumn{4}{|c|}{$\begin{array}{l}\text { Distance between adjacent birds } \\
\text { along legs of formation (meters) }\end{array}$} \\
\hline \multicolumn{2}{|c|}{ Bird No. } & \multicolumn{2}{|c|}{ Bird No. } & \multicolumn{2}{|c|}{ Bird No. } & \multicolumn{2}{|c|}{ Bird No. } & \multicolumn{2}{|c|}{ Bird No. } & \multicolumn{2}{|c|}{ Bird No. } \\
\hline $1-2$ & 3.4 & $2-3^{\prime}$ & 4.2 & $1-2$ & 7.5 & $1-2^{\prime}$ & 5.2 & $2-3$ & 3.2 & $1-2$ & 3.9 \\
\hline $2-3$ & 12.8 & $3^{\prime}-4^{\prime}$ & 2.7 & $2-3$ & 3.8 & $2^{\prime}-3^{\prime}$ & 4.0 & $3-4$ & 2.8 & $2-3^{\circ}$ & 3.6 \\
\hline $3-4$ & 5.2 & $4^{\circ}-5^{\prime}$ & 3.3 & $3-4$ & 3.6 & $3^{\circ}-4^{\prime}$ & 5.2 & $4-5$ & 2.8 & $3^{0}-4^{\circ}$ & 3.9 \\
\hline $4-5$ & 6.7 & $5^{\prime}-6^{\prime}$ & 4.4 & $4-5$ & 4.2 & $4^{\prime}-5^{\prime}$ & 8.3 & & & $4^{\prime}-5^{\prime}$ & 2.5 \\
\hline $5-6$ & 2.8 & & & $5-6$ & 3.1 & $5^{\circ}-6^{\prime}$ & 3.1 & & & $5^{\circ}-6^{\circ}$ & 2.8 \\
\hline $6-7$ & 2.6 & & & $6-7$ & 3.6 & & & & & & \\
\hline $7-8$ & 3.1 & & & & & & & & & & \\
\hline $8-9$ & 3.1 & & & & & & & & & & \\
\hline $9-10$ & 2.6 & & & & & & & & & & \\
\hline Mean & 4.7 & & 3.6 & & 4.3 & & 5.0 & & 2.9 & & 3.3 \\
\hline \multicolumn{4}{|c|}{$\begin{array}{l}\text { Mean for entire formation: } \\
\text { S.D. }=2.4\end{array}$} & \multicolumn{4}{|c|}{$\begin{array}{r}\text { Mean for entire formation: } \\
\text { S.D. }=1.7 \\
\end{array}$} & \multicolumn{4}{|c|}{$\begin{array}{r}\text { Mean for entire formation: } \\
\text { S.D. }=0.46\end{array}$} \\
\hline
\end{tabular}




\section{TABLE 4}

Wing-beat Frequencies

\begin{tabular}{|c|c|c|c|c|c|c|c|c|c|c|c|}
\hline \multicolumn{6}{|c|}{ Formation $\mathrm{B}$} & \multicolumn{6}{|c|}{ Formation $\mathrm{C}$} \\
\hline \multicolumn{6}{|c|}{ True angle $=29.5^{\circ}$} & \multicolumn{6}{|c|}{ True angle $=32.25^{\circ}$} \\
\hline \multicolumn{6}{|c|}{ Wing-beat frequency } & \multicolumn{6}{|c|}{ Wing-beat frequency } \\
\hline $\begin{array}{c}\text { Bird } \\
\# \\
\end{array}$ & $\begin{array}{l}\text { \# frames } \\
\text { per flap }\end{array}$ & $\begin{array}{l}\# \text { flaps } \\
\text { per min }\end{array}$ & $\begin{array}{c}\text { Bird } \\
\#\end{array}$ & $\begin{array}{l}\text { \# frames } \\
\text { per flap }\end{array}$ & $\begin{array}{l}\text { \# flaps } \\
\text { per min }\end{array}$ & $\begin{array}{c}\text { Bird } \\
\#\end{array}$ & $\begin{array}{l}\text { \# frames } \\
\text { per flap }\end{array}$ & $\begin{array}{l}\text { \# flaps } \\
\text { per min }\end{array}$ & $\begin{array}{c}\text { Bird } \\
\#\end{array}$ & $\begin{array}{l}\text { \# frames } \\
\text { per flap }\end{array}$ & $\begin{array}{l}\text { \# flaps } \\
\text { per min }\end{array}$ \\
\hline 1 & 4.75 & $227 \cdot 4$ & $2^{\prime}$ & $4 \cdot 50$ & 240.0 & 1 & 4.00 & 270.0 & $3^{\prime}$ & 4.25 & 254.4 \\
\hline 2 & 4.75 & $227 \cdot 4$ & $3^{\circ}$ & 4.75 & 227.4 & 2 & 4.40 & $245 \cdot 4$ & $4^{\circ}$ & 5.00 & 216.0 \\
\hline 3 & $4 \cdot 50$ & 240.0 & $4^{\circ}$ & 4.75 & 227.4 & 3 & 4.40 & $245 \cdot 4$ & $5^{\prime}$ & 5.00 & 216.0 \\
\hline 4 & $4 \cdot 50$ & 240.0 & $5^{\circ}$ & 4.25 & 254.4 & 4 & 4.80 & 225.0 & $6^{\prime}$ & 4.40 & 245.4 \\
\hline 5 & $4 \cdot 50$ & 240.0 & $6^{\circ}$ & 4.75 & $227 \cdot 4$ & 5 & 4.00 & 270.0 & & & \\
\hline 6 & $4 \cdot 50$ & 240.0 & & & & & & & & & \\
\hline 7 & $4 \cdot 50$ & 240.0 & & & & & & & & & \\
\hline Mean & $4 \cdot 57$ & 239.3 & & 4.60 & 235.3 & & $4 \cdot 30$ & 251.2 & & 4.70 & 233.0 \\
\hline
\end{tabular}


TABLE 4 - continued

Formation D

True angle $=44.0^{\circ}$

Wing-beat frequency

\begin{tabular}{c|c|c|c|c|c}
\hline $\begin{array}{c}\text { Bird } \\
\#\end{array}$ & $\begin{array}{c}\text { \# frames } \\
\text { per flap }\end{array}$ & $\begin{array}{c}\text { \# flaps } \\
\text { per min }\end{array}$ & $\begin{array}{c}\text { Bird } \\
\#\end{array}$ & $\begin{array}{c}\text { \# frames } \\
\text { per flap }\end{array}$ & $\begin{array}{l}\text { \# flaps } \\
\text { per min }\end{array}$ \\
\hline 1 & 5.00 & 216.0 & $2^{\circ}$ & 5.00 & 216.0 \\
\hline 2 & 4.67 & 231.0 & $3^{\circ}$ & 4.67 & 231.0 \\
\hline 3 & 4.67 & 231.0 & $4^{\circ}$ & 4.67 & 231.0 \\
\hline 4 & 4.67 & 231.0 & $5^{\circ}$ & 4.67 & 231.0 \\
\hline 5 & 4.67 & 231.0 & $6^{\circ}$ & 4.67 & 231.0 \\
\hline 6 & 4.67 & 231.0 & $7^{\circ}$ & 4.33 & 249.6 \\
\hline 7 & 4.67 & 231.0 & $8^{\circ}$ & 4.67 & 231.0 \\
\hline 8 & 4.67 & 231.0 & $9^{\circ}$ & 4.33 & 249.6 \\
\hline Mean & 4.71 & 229.1 & & 4.63 & 233.8 \\
\hline
\end{tabular}

Overall mean: 4.6 frames/wing-beat $\left(S_{0}\right.$. $=0.27$ )

237 wing-beats/minute

4 wing-beats/second (S.D. $=0.225$ ) 


\section{DISCUSSION AND CONCLUSION}

The results of this study indicate a great amount of position change within the majority of the formations filmed, and hence little persistence of formation shape and angle. With constant shifts in position, and perhaps changes in drag distribution, it is difficult to support an hypothesis of energy savings from equal drag distribution in these formations. Possibly the formations filmed in this study are not typical of flocks positioned for long-distance flight. The flocks were concentrated in a large refuge offering them shelter and surrounding fields for feeding. At dawn most flocks left the area in large, vocal groups, but since the observers were unable to follow the flocks, it is not known if these departures indicated the beginning of the day's migration or a local foraging movement. At dawn the birds left over a short time period, forming groups of hundreds of birds, changing positions and formation types constantly as they flew farther away. The morning flocks probably took off in unison because the stimulus for flight was very strong, as so many birds were concentrated in one area. Several minutes of flight may have been required before family units could gather their members and position themselves into a formation, or for the birds to establish a formation with equal drag distribution. During the day 
the huge flocks broke into smaller units, probably due to variations among the flocks in direction (route) and speed of flight. By sunset the flocks were generally smaller, and landed in the refuge or near-by fields over a two-hour period. Perhaps the five "persistent" formations used to measure angles and distances in this study, were flocks which had taken off earlier from another area and were already "in position", or flocks which were not ready to land as they flew over the refuge. Additional (unfilmed) personal observations indicated that short, local flights (e.g. from resting to feeding grounds) usually involved nonpersistent formations, concurring with the observations of Howley (1884) and Bent (1925) that Vee formations are used for long-distance flight.

As seen in Table 1, $82 \%$ of the 104 formations filmed were linear formations. This percentage may not indicate a preference on the part of Canada Geese for this formation type, but instead may indicate non-random filming. However, most takes involved more than one flock, and some takes were huge groups of flocks which could be considered random samples. The non-linear formations (clusters) seemed less persistent than other formations, and possibly are transition stages between linear formations. Cluster formations frequently were noted (although not always filmed) imnediately after a flock took off, or as a flock was landing. The data indicate that Canada Geese "prefer" linear formations, particularly the echelon/column. 
The data do not indicate a preference for specific formation types with variation in wind conditions, but there were preferences for flight in variable wind directions and speeds. Although the wind speed was less than $9 \mathrm{kph}(5 \mathrm{mph})$ only approximately $30 \%$ of the filming time, $60 \%$ of all flocks were filmed while flying in this wind speed range. Wind with speeds over $18 \mathrm{kph}$ was extremely gusty and variable; only one flock (an echelon) was filmed in winds of over $35 \mathrm{kph}$. Allen (1939) and Cone (1968) suggested that a constant moderate wind (26-35 kph) will cause a bird little trouble in flight, but variability (either in strength or direction) of winds, such as strong gusts, make flight difficult. The apparent avoidance of high wind speeds seen in this study concurs with my observations of migratory Canada Geese in coastal Rhode Island, where the birds seldom fly when winds are greater than $44 \mathrm{kph}$ (25 mph).

The flocks demonstrated a definite preference for a specific wind direction in relation to the direction of flock movement. Seventy-two percent of the formations flew in a crosswind. Wind direction varied from southeast to northwest, with prevailing westerly winds. Flock directions varied to all compass points, although most of the flocks flew south or southeast. Possibly, this "preference" for crosswinds was a necessity, since the birds were flying south, and the prevailing winds were transverse to this flight path. However, Table 2 shows that in winds of over 
$9 \mathrm{kph}$ all but 3 formations out of 42 flew with a crosswind. In wind speeds less than $9 \mathrm{kph}$ almost one-half the formations were flying with tailwinds. These data indicate a preference for crosswinds in wind speeds of greater than $9 \mathrm{kph}$, perhaps due to the variability of these winds. Allen (1939) suggested that birds might avoid strong, gusty tailwinds, since such winds would disturb the feathers and make smooth flight difficult to maintain. As discussed earlier, Pennycuick (1968) hypothesized that geese might use crosswinds as a secondary soaring technique to increase range. The data presented in this study cannot prove his theory, but indicate that further study might be worthwhile. Lissaman and Shollenberger suggested that Vee formations might be able to utilize tailwinds to greatest advantage, but they did not explain their reasoning. Of the five formations analyzed in this study, four were flying in tailwinds, but as these winds were at speeds of less than $11 \mathrm{kph}$. I cannot make any conclusions based on their proposal.

The five Vee formations analyzed (see Figures 5-9) ranged in numbers of birds from 9 to $39($ S.D. $=10.8)$; the angles exhibited a more narrow range, from $27.5^{\circ}$ to $44.0^{\circ}$ $\left(S \cdot D .=5 \cdot 7^{\circ}\right)$. These angles are far more acute than previous hypothetical models predicted (Poncy, 1941; Lissaman and Shollenberger, 1970). For example, according to Poncy's models, the angle of goose formations should approach the angle of the cormorant formation (slightly greater than $90^{\circ}$ ), because geese are shaped similar to cormorants. It is 
understandable how hypotheses concerning the function of the Vee formation, based on the assumption of an obtuse Vee angle, could be drawn from visual observation, because the apparent angle of a formation is deceptive.

In this study, the Vee angles did not vary consistently with the number of birds in the flocks, but they appeared to vary with the distance between adjacent birds. The data suggest (although inconclusively) decreasing Vee angles with increased spacing between birds (see Table 3). From the birds' visual standpoint this seems logical if an angle is very acute, and the birds very close together, there is likely to be visual impairment to the front; with a more obtuse angle spacing can be closer with no visual problems. This is also logical aerodynamically; the more obtuse the angle, the closer the birds would have to be to gain lift from the wing-tip vortices.

The distances between adjacent birds along the leg of a formation were variable, particularly within formations $A$ and $B(S . D .=2.6$ and 1.6 meters, respectively). Wingbeat frequencies, however, varied little (S.D. $=0.225$ beats/ second) remaining at 4 beats/second. These frequencies are within published observations, which range from 2 to 3 beats/second (Van Wormer, 1968) to 5 beats/second (Cone, 1968). Nachtigall (1970) demonstrated wing-beat phase relationships among birds flying in Vee formations; consistent phase relationships were not found in this study. The data suggest that the birds' wings are acting as independent 
oscillators of slightly-varying frequencies; sometimes some birds will appear to be in phase, but these relationships will not persist unless the frequencies are identical. If the birds are employing the Vee formation for aerodynamic advantage, then several questions arise in relation to the distances between brids, and the wing-beat frequencies. In any one formation, all the birds are flying in the same direction relative to the wind, and at the same speeds (otherwise the formation would not persist); the similar wing-beat frequencies also indicate conformity of speed. The distances between birds varied from 2.5 meters to 12.8 meters. How can the birds utilize wing-tip vortices, considering some of the large distances found (e.g. 8-12 meters)? In light of the variability in distance and wing-beat phase relationships, can there be equal drag distribution?

Future investigations should resolve these questions. Studies of premigratory hyperphagia in geese and correlation with energy requirements during migration are needed. In such a study the following questions should be asked: How long can a lone goose fly non-stop? Does this distance differ for a formation and among different formations? Does the amount of energy utilized differ between lone birds, and formations? What effects do varying winds have on energy utilization, and on formation types? Secondly, flocks of geese should be filmed (preferably with $16 \mathrm{~mm}$ film) when they are definitely in migratory flight formations. Stere- 
oscopy might be more accurate than projective geometry for the actual filming and analysis. More wind-tunnel studies on the aerodynamics of the flapping bird wing are needed, especially studies of the shape and strength of the wing-tip vortices.

The possibility remains that goose formations are not aerodynamically advantageous, but serve a different function in species survival. As mentioned previously, formations of geese and other water birds may allow each bird to see most of the other birds in the flock; the flock is thus able to remain a unit. The constant vocalization among flocking geese appears to be an additional method of maintaining unity. Perhaps an advantage to this unity is increased navigational ability, i.e. the birds are able to "pool" their knowledge on routes, safe resting areas, and feeding locations. First-year juvenile Canada Geese may be unable to migrate without the aid of experienced adults, unlike the young of some other species of birds. Studies on goose orientation and premigratory restlessness would be of interest, as would studies of the navigational abilities of lone geese compared with geese in flocks. This study has presented a unique method to determine the angles and spacing between birds in a Vee formation, and is the first study in which these problems have been explored empirically. The Canada Geese studied demonstrated a preference for linear formations, and it is very likely that a partial function of such linear formations is to 
provide each bird with a clear view of the bird ahead, and the space to the front, thus enabling the flock to remain a unit. Flock unity may be important in migratory navigation.

The Vee angles calculated were more acute than previous models had hypothesized, and I suspect that earlier workers failed to account for problems of perspective. Wing-beat frequencies varied slightly, and the values were constant with published data (Van Wormer, 1968; Cone, 1968). However, the slight differences between individual birds leads to the idea that the birds' wings are independent oscillators; wing-beat phase relationships were not demonstrated, contrary to the study of Nachtigall (1970). The consistent speeds of the birds within the formations analyzed, and the variability in distance between birds within at least two of the formations, suggest that it is unlikely these particular formations are using the Vee (or Jay) for the aerodynamic advantage of equalizing induced drag among flock members. Possibly the formations filmed in this study are atypical of flocks positioned for a long migratory flight. Further work is needed to resolve the questions raised by these studies. 


\section{LITERATURE CITED}

Allen, F.H. 1939. Effect of wind on flight speeds. Auk 56: $291-303$.

Austin, O.L. 1961. Water and Marsh Birds of the World.

Golden Press, New York. 223 p.

Beer, J.R. 1958. The composition of bird flocks. Flicker $30.78-83$.

Bent, A.C. 1925. Life Histories of North American Wild

Fowl. Pt. II. Dover Publications Inc., New York. 314 p. Brown, R.H.J. 1953. The flight of birds. II. Wing function in relation to flight speed. J. Exp. Biol. 30: $90-103$.

- 1963. The flight of birds. Biol. Rev. 38:

$460-489$.

Collias, N.E. 1952. Development of social behavior in birds. Auk 69: 127-157.

Cone, C.D. 1968. The aerodynamics of flapping birdflight. Va. Inst. Mar. Sci. Spec. Sci. Rep. 52: 133 p. Cottam, C., C.S. Williams, and C.A. Sooter. 1942. Flight and running speed of birds. Wil. Bull. 54, 121-131. Darling, F.F. 1938. Bird Flocks and the Breeding Cycle. Cambridge Univ. Press, Cambridge. 179 p. - 1952. Social behavior and survival. Auk 69: 183-191. 
Davis, W.M. 1896. The soaring of birds and currents of air. Auk 13: 92.

Delacour, J. and E. Mayr. 1945. The family Anatidae. Wil. Bull. 57: 3-55.

Dwinnell, J.H. 1949. Principles of Aerodynamics. McGrawHill Book Co., Inc., New York. 391 p. Elder, W.H. and N.L. Elder. 1949. Role of the family in the formation of goose flocks. Wil. Bull. 61: 133-140. Emlen, J.T. 1952. Flocking behavior in birds. Auk 69: $160-170$.

Forbush, E.H. 1912. A History of the game birds, wildfowl, and shore birds of Massachusetts and adjacent states. Mass. State Board of Agric., Boston, Wright, and Potter Co., Boston. $622 \mathrm{p}$.

George, J.C. and A.J. Berger. 1966. Avian Myology. Academic Press, New York, 500 p.

Geyr von Schweppenburg, H. 1952. Vorteile der Zuggeselligkeit. Vogelwarte 16: 116-119.

Greenewalt, C.H. 1960. The wings of insects and birds as mechanical oscillators. Proc. Amer. Phil. Soc. 1048 605-611.

- 1962. Dimensional relationships of flying animals. Smithson. misc. Collns. 144, 1-46. Hanson, H.C. 1965. The Giant Canada Goose. Southern Illinois Univ. Press. Carbondale, Ill. 226 p.

Heppner, F.H. MS. Classification and possible advantages of avian flight formations. 
Howley, J.P. 1884. The Canada Goose. Auk 1: 309-313. King, J.R. and D.S. Farner. 1965. Studies of far deposition in migratory birds. Ann. N.Y. Acad. Sci. 131: $422-440$.

Lissaman, P.B.S. and C.A. Shollenberger. 1970. Formation flight of birds. Science 168, 1003-1005.

Lorenz, K.Z. 1937. The companion in the bird's world. Auk 54: 245-273.

Marshall, A.J. 1961. Biology and Comparative Physiology of Birds. II. Academic Press, N.Y. 468 p. Mitchell, K.D.G. 1955. Aircraft observations of birds in flight. Brit. Birds. 48, 59-70.

Munk, M.M. 1933. The Principles of Aerodynamics. The Ronald Press Co., New York. 252 p. Nachtigall, W. 1970. Verbandflug der Gänse. (Phase relationship in the wing beat of geese flying in "V" formation.) Z. vergl. Physiologie. 67: 414-422. Nisbet, I.C.T. 1963. Weight-loss during migration. II.: Review of other estimates. Bird-Banding 348 139-159. - 1967. Aerodynamic theories of flight versus physiological theories. Bird-Banding 38: 306-316. - W.H. Drury Jr., and J. Baird. 1963. Weight

loss during migration. I. Deposition and consumption of fat by the Blackpoll Warbler Dendroica striata. Bird-Banding 34: 107-138. Parkinson, L.R. 1944. Aerodynamics. The Macmillan Co., New York. 112 p. 
Parrott, G.C. 1970. Aerodynamics of gliding flight of a black vulture, Coragyps atratus. J. Exp. Biol. 53: 363-374.

Pennycuick, C.J. 1969. The mechanics of bird migration. Ibis III: 525-556.

Phillips, J.C. 1910. Notes on the autumn migration of the Canada Goose in eastern Massachusetts. Auk 27: 263271.

Poncy, R. 1941. Formations angulaires des vols de quelques espèces d'Oiseaux migrateurs et les réactions observées (particulierement chez les Canards). (Angular formations of the flight of some species of migrating birds and the observed reactions (particularly among ducks.)). Der Ornithologische Boebachter 1: 17-18. Preston, J.W. 1892. Notes on bird flight. Ornith. Olog. $17: 41-42$.

Queeny, E.M. 1947. Prairie Wings. J.B. Lippincott, New York. 250 p.

Raspet, A. 1950. Performance measurements of a soaring bird. Aeron. Engin. Rev. 9: 14-17. - 1960. Biophysics of bird flight. Science 132: $191-200$.

Raveling, D.G. and E.A. LeFebvre. 1967. Energy metabolism and theoretical flight range of birds. Bird-Banding 38: 97-113.

Ruthven, J.A. and W. Zimmerman. 1965. Top Flight: Speed Index to Waterfowl of North America. Moebius Co. Milwaukee, $112 \mathrm{p}$. 
Savile, S.B.0. 1957. Adaptive evolution in the avian wing. Evolution II: 212-224。

Schaefer, G.W. 1968. Energy requirements of mj.gratory flight. Ibis 110: 413-414.

Slaby, S.M. 1966. Fundamentals of Three-Dimensionall Descriptive Geometry. Harcourt, Brace, and World, Inc., New York. 383 p.

Storer, J.H. 1948. The Flight of Birds. Cranbrook Inst. of Sci. Bull. No. 48. Cranbrook Press, Bloomfield Hills, Michigan. $94 \mathrm{p}$.

Terres, J.K. 1968. Elashing Wings: The Drama of Bird

Flight. Doubleday and Company, Inc., Garden City, New York. $177 \mathrm{p}$.

Tucker, V.A. 1970. Energetic cost of locomotion in animals. Comp. Biochem. Physiol. 34: 841-846. - 1971. Flight energetics in birds. Amer. Zool.

II: $115-124$. and G.C. Parrott. 1970. Aerodynamics of gliding flight in a falcon and other birds. J. Exp. Biol. $52: 345-367$. and Schmidt-Koenig. 1971. Flight speed of birds in relation to energetics and wind directions. Auk 88 : 97-10?.

Van Wormer, J. 1968. The World of the Canada Goose. J.B. Lippincott Co., New York. 192 p. werth, I. 1958. The problem of flocking in birds. Proc. Internatl. Ornithol. Congr. 12: 744-748. 